\title{
Harnessing Ion-Binding Sites for GPCR Pharmacology
}

\author{
Barbara Zarzycka, Saheem A. Zaidi, Bryan L. Roth, and Vsevolod Katritch
}

Departments of Biological Sciences (B.Z., S.A.Z., V.K.) and Chemistry (V.K.), Bridge Institute, Michelson Center for Convergent Bioscience, University of Southern California, Los Angeles, California; and Department of Pharmacology (B.L.R.) and Division of Chemical Biology and Medicinal Chemistry, Eshelman School of Pharmacy (B.L.R.), University of North Carolina at Chapel Hill, Chapel Hill, North Carolina

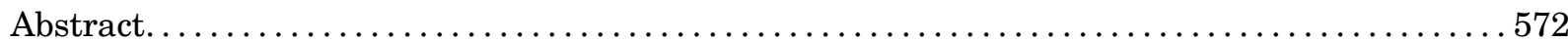

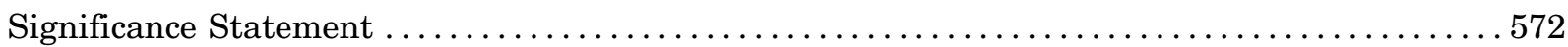

I. Historical Overview ..................................................... 572

II. Structural Data for Conserved and Nonconserved Ion Binding Sites in G-Protein-Coupled

Receptors ..................................................... 576

A. Conserved Sodium Binding Site in Class A G-Protein-Coupled Receptors . . .......... 576

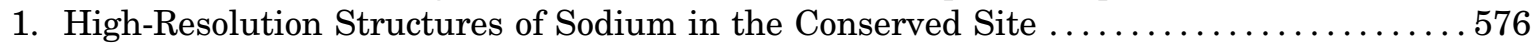

2. Sodium Ion Detection Criteria ................................... 577

3. Lower Resolution Inactive State Structures of Class A Compatible with Sodium Ion

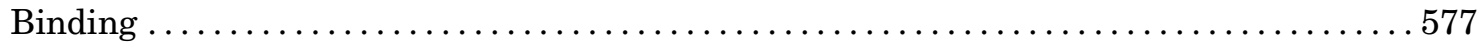

4. Structures of Active State G-Protein-Coupled Receptors Are Incompatible with

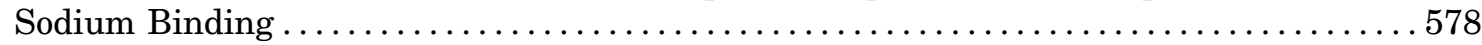

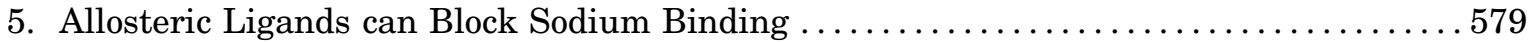

6. Mutations Abolishing Sodium Binding ............................... 579

B. G-Protein-Coupled Receptors that Lack the Conserved Sodium Site................. 580

1. Some Class A G-Protein-Coupled Receptors Lack Specific Sodium Site............ 580

2. Non-Class A G-Protein-Coupled Receptors Lack Conserved Sodium Sites in 7-

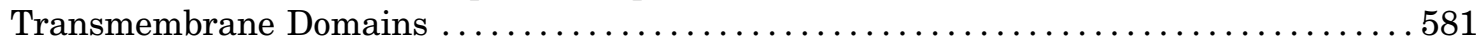

C. Nonconserved Ion Binding Sites in G-Protein-Coupled Receptors................ 581

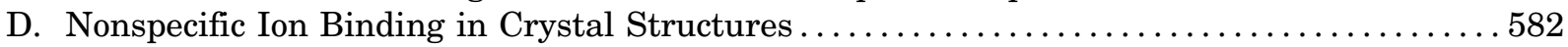

III. Functional Role-Why is Sodium So Special for Class A G-Protein-Coupled Receptors? . . . . . 582

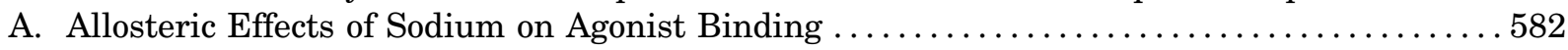

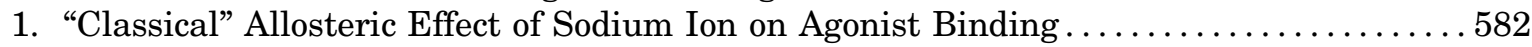

2. Binding of Sodium Not Always Detected by a "Classical" Allosteric Effect........... 584

B. Evidence for the Functional Importance of the Sodium Ion Site . . . . . . . . . . . . . . 584

1. Direct Functional Effects of Sodium Ion Presence .......................... 584

2. Mutations in Sodium Ion Pocket Reduce or Abolish Receptor Stimulation by

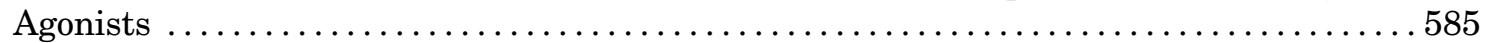

3. A Gain of Function by Introducing Acidic Residues in Sodium Ion Pocket.......... 586

4. Disease-Associated Mutations in the Sodium Pocket...................... 586

C. Mechanism of Sodium Ion Functional Involvement ......................... 586

1. Sodium as an Allosteric Cofactor of Class A G-Protein-Coupled Receptor Signaling . ...586

D. Other Potential Functional Effects of the Conserved Sodium Ion Binding .............587

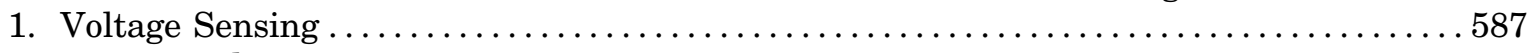

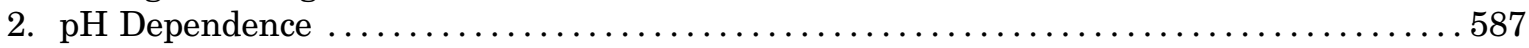

IV. Ion Binding Sites as Ligand Targets—New Approaches to Design Functional Properties ..... 587

Address correspondence to: Dr. Vsevolod Katritch, University of Southern California, 1002 West Childs Way, MCB-317, Los Angeles, CA 90089. E-mail: katritch@usc.edu; or Dr. Bryan L. Roth, University of North Carolina at Chapel Hill, 120 Mason Farm Rd., CB \# 7365 Chapel Hill, NC 27599-7365. E-mail: bryan_roth@med.unc.edu

The research was supported by National Institutes of Health National Institute on Drug Abuse Grants [DA038858, P01DA035764, R37DA035764]; National Institute of Mental Health Grant [R01MH112205]; the National Institute of Mental Health Psychoactive Drug Screening Program; and the Michael Hooker Distinguished Professorship to B.L.R. and The Netherlands Association for Scientific Research Rubicon fellowship [019.161LW.035].

https://doi.org/10.1124/pr.119.017863. 
A. Targeting Nonconserved Ion Binding Sites for Subtype Selectivity $\ldots \ldots \ldots \ldots \ldots \ldots \ldots 58$

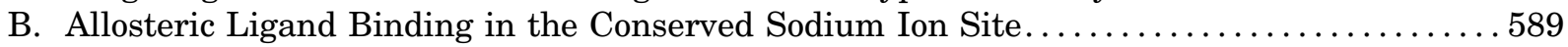

C. Targeting Sodium Ion with Bitopic Ligands $\ldots \ldots \ldots \ldots \ldots \ldots \ldots \ldots \ldots \ldots \ldots \ldots \ldots \ldots$

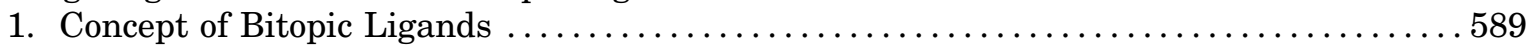

2. Structure-Based Design of Bitopic Ligands for the Sodium Ion Site ............. 589

V. Biophysical and Computational Approaches for Studying Allosteric Ions ................ 590

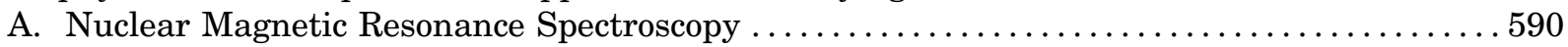

1. Study of G-Protein-Coupled Receptor Dynamics with and without Sodium Ion Site.... 590

2. Direct Nuclear Magnetic Resonance Assessment of Allosteric Sodium Ion Binding

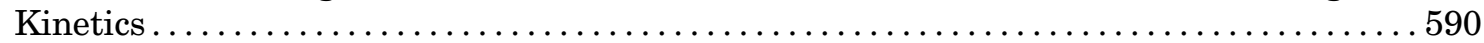

3. Binding and Effect of Divalent Ions in $\mathrm{A}_{2 \mathrm{~A}}$ Adrenergic Receptor is Potentially Nonspecific..................................................... 590

B. Molecular Dynamic Simulations . ................................... 590

1. Sodium Access and Universality of Sodium Ion Binding in Class A G-Protein-

Coupled Receptors........................................... 590

2. Molecular Dynamic Simulations Corroborate New Functional Hypotheses .......... 591

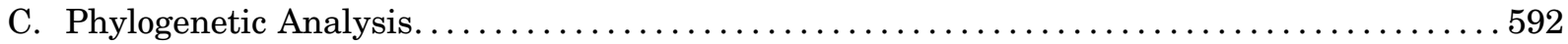

VI. Unanswered Questions and Future Perspectives ............................. 592

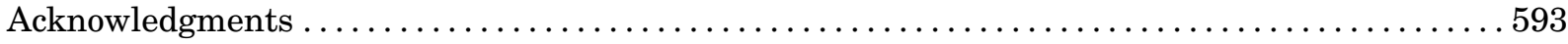

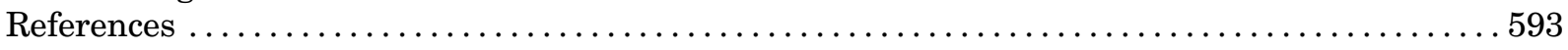

\begin{abstract}
Endogenous ions play important roles in the function and pharmacology of G-protein coupled receptors (GPCRs). Historically the evidence for ionic modulation of GPCR function dates to 1973 with studies of opioid receptors, where it was demonstrated that physiologic concentrations of sodium allosterically attenuated agonist binding. This $\mathrm{Na}^{+}$-selective effect was distinct from effects of other monovalent and divalent cations, with the latter usually counteracting sodium's negative allosteric modulation of binding. Since then, numerous studies documenting the effects of mono- and divalent ions on GPCR function have been published. While ions can act selectively and nonselectively at many sites in different receptors, the discovery of the conserved sodium ion site in class $A$ GPCR structures in 2012 revealed the unique nature of $\mathrm{Na}^{+}$site, which has emerged as a near-universal site for allosteric modulation of class A GPCR structure and function. In this review, we synthesize and highlight
\end{abstract}

recent advances in the functional, biophysical, and structural characterization of ions bound to GPCRs. Taken together, these findings provide a molecular understanding of the unique roles of $\mathrm{Na}^{+}$and other ions as GPCR allosteric modulators. We will also discuss how this knowledge can be applied to the redesign of receptors and ligand probes for desired functional and pharmacological profiles.

Significance Statement - The function and pharmacology of GPCRs strongly depend on the presence of mono and divalent ions in experimental assays and in living organisms. Recent insights into the molecular mechanism of this ion-dependent allosterism from structural, biophysical, biochemical, and computational studies provide quantitative understandings of the pharmacological effects of drugs in vitro and in vivo and open new avenues for the rational design of chemical probes and drug candidates with improved properties.

\section{Historical Overview}

Endogenous ions are involved in all aspects of human biology, including their key roles in the function and pharmacology of GPCRs, which comprise the largest family of clinically relevant protein targets (Lagerström and Schiöth, 2008; Katritch et al., 2013; Hauser et al., 2017). GPCRs signal both at the plasma membrane and in intracellular membranes, including endosomes and golgi (Calebiro et al., 2010; Irannejad et al., 2013; Vilardaga et al., 2014; Godbole et al., 2017; Eichel and von Zastrow, 2018), and are likely exposed to large spatiotemporal variations in ionic and $\mathrm{pH}$ conditions that may affect their function. Thus, for instance, extracellular $\mathrm{Na}^{+}$is normally maintained in 135-145 mM range, while its intracellular levels are about 10 times

ABBREVIATIONS: $\mathrm{A}_{2 \mathrm{~A}} \mathrm{R}, \mathrm{A}_{2 \mathrm{~A}}$ adenosine receptor; BLT1, leukotriene B4 receptor 1; cAMP, cyclic adenosine monophosphate; CaSR, calcium sensing receptor; CB1, cannabinoid receptor type 1; CCR2, C-C chemokine receptor type 2; CLTR1, cysteinyl leukotriene receptor 1; CPMG, Carr Purcell Meiboom and Gill NMR; DOR, delta opioid receptor; DRD2, dopamine receptor D2; DRD3, dopamine receptor D3; DRD4, dopamine receptor D4; EC, extracellular; ECL, extracellular loop; ECL2, extracellular loop 2; EM, electron microscopy; EP3, prostaglandin E receptor subtype $\mathrm{EP} 3$; $\mathrm{ET}_{\mathrm{A}}$, endothelin $\mathrm{ET}_{\mathrm{A}}$ receptor; ETB1, endothelin ETB1 receptor; GPCR, G-protein-coupled receptors; HMA, 5$\left(N, N\right.$-hexamethylene)amiloride; $\mathrm{MD}$, molecular dynamics; M2R, muscarinic acetylcholine receptor $2 ; \mathrm{MOR}, \mu$-opioid receptor; Na ${ }^{+}$, sodium ion; NAM, negative allosteric modulation; NMR, nuclear magnetic resonance; NTS, neurotensin receptor; NTSR1, neurotensin receptor type 1; NTSR2, neurotensin receptor type 2; PAM, positive allosteric modulation; PAR1, protease-activated receptor 1; PAR2, protease-activated receptor $2 ; \mu$-OR, $\mu$-opioid receptor; $5 \mathrm{HT}_{2 \mathrm{~B}}, 5$-hydroxytryptamine receptor $2 \mathrm{~B} ; 7 \mathrm{TM}, 7$ transmembrane. 
lower in most cells (Lodish et al., 2000); intracellular sodium levels rapidly increase during depolarization in neurons. Also, some GPCRs are directly (Wingler et al., 2019) and selectively modulated by inorganic ions as a part of their physiologic function, e.g., CaSR by $\mathrm{Ca}^{2+}$ (Silve et al., 2005) and GPR39 by $\mathrm{Zn}+$ (Sato et al., 2016). Other GPCRs are proton sensing, including GPR68, GPR4, TDAG8, and G2A (Ludwig et al., 2003; Radu et al., 2005; Yang et al., 2007; Liu et al., 2010; Huang et al., 2015b). In this review though, we will mostly focus on the function of endogenous ligands, and therapeutic drugs, being allosterically modulated by ions interacting with GPCRs.

Historically, the first evidence for ionic modulation of GPCRs dates well before they were recognized as a large family of receptors sharing a common seventransmembrane (7TM) architecture. In 1973, studies of opioid receptors showed that agonist binding is negatively modulated by monovalent cations like $\mathrm{Na}^{+}$(Pert et al., 1973; Pert and Snyder, 1974), while being positively modulated by divalent cations (Pasternak et al., 1975). Several subsequent studies provided biochemical data suggesting that these effects were mediated by an allosteric mechanism (Simon and Groth, 1975; Horstman et al., 1990). A similar negative allosteric modulation of agonist binding affinity was soon discovered for many other class A GPCRs including adrenergic (Tsai and Lefkowitz, 1978), dopaminergic (Neve, 1991;
Neve et al., 1991) and somatostatin (Kong et al., 1993) receptors. Since then, hundreds of papers have appeared documenting the actions of sodium, as well as other cations and anions on the function of many GPCRs [see Katritch et al. (2014) and (Strasser et al., 2015) for review].

Moreover, high-resolution structural information for GPCRs and their complexes, which has emerged in the past few years (Liu et al., 2012b; Fenalti et al., 2014; Miller-Gallacher et al., 2014; Wang et al., 2017) has made it possible to identify a variety of ion binding sites in GPCRs (Fig. 1; Table 1). While some of the ions, like the multiple $\mathrm{Zn}^{2+}$ and $\mathrm{Hg}^{2+}$ ions in rhodopsin structures were introduced to assist crystallization and/or anomalous diffraction phasing (Teller et al., 2001), many other ion binding sites may be relevant for endogenous ligand binding at specific receptors. For example, the crystallographically observed $\mathrm{PO}_{4}^{3-}$ site in $\mathrm{H} 1$ histamine receptor (Shimamura et al., 2011) or $\mathrm{Na}^{+}$ binding in the extracellular loop in the $\beta_{1} \mathrm{AR}$ adrenergic receptor (Miller-Gallacher et al., 2014).

Only the sodium site, however, stands out as highly conserved among most class A GPCRs (Katritch et al., 2014) and potentially tracing its origin to other distant 7TM relatives like prokaryotic channel rhodopsins (Shalaeva et al., 2015). This site binds allosteric sodium in the middle of the 7TM helical bundle of class A GPCRs (Fig. 2, A and B), anchored at the most

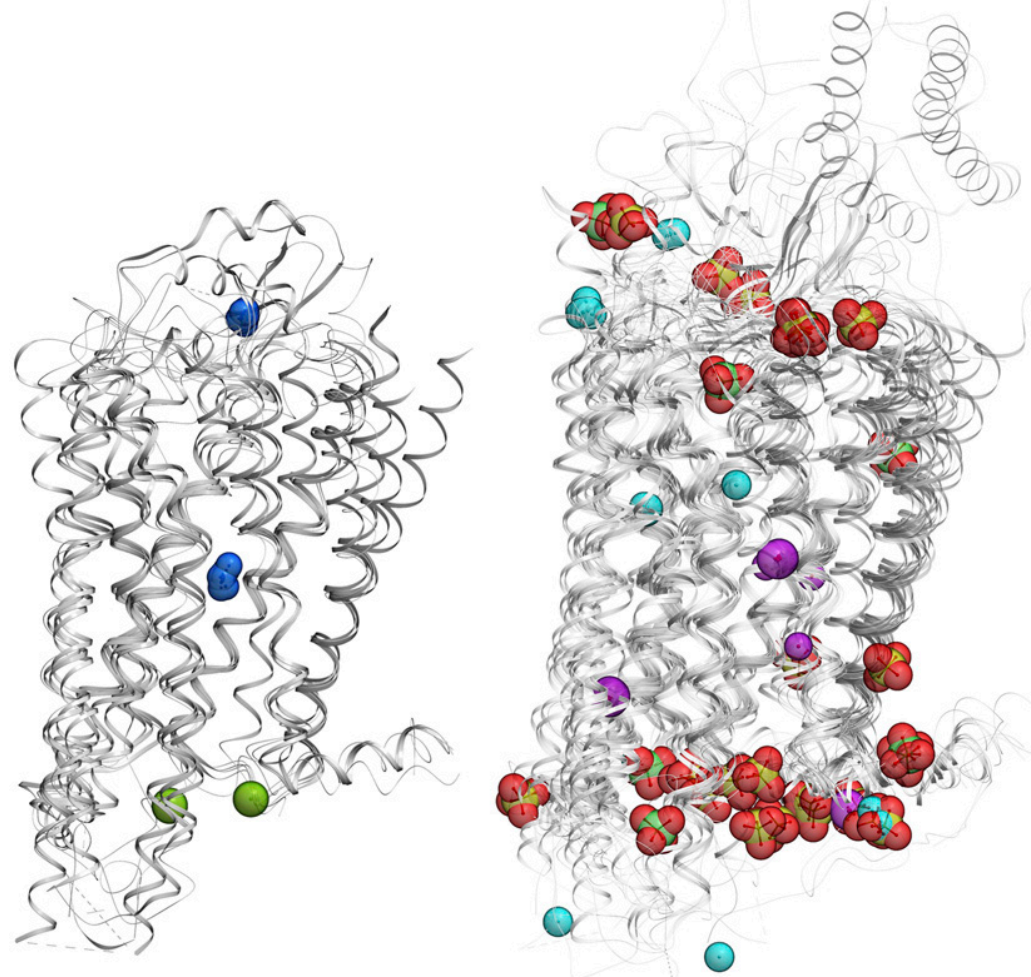

Fig. 1. Ions identified in GPCR crystal structures. (A) Monovalent ions: $\mathrm{Na}^{+}$(blue) and $\mathrm{Cl}^{-}$(green). (B) Polyvalent ions $\mathrm{Zn}^{2+}$ (magenta), $\mathrm{Hg}^{2+}$ (cyan), $\mathrm{PO}^{3-}$ (phosphate colored green), $\mathrm{SO}^{2-}$ (sulfur colored yellow). GPCR structures shown as gray cartoons. 


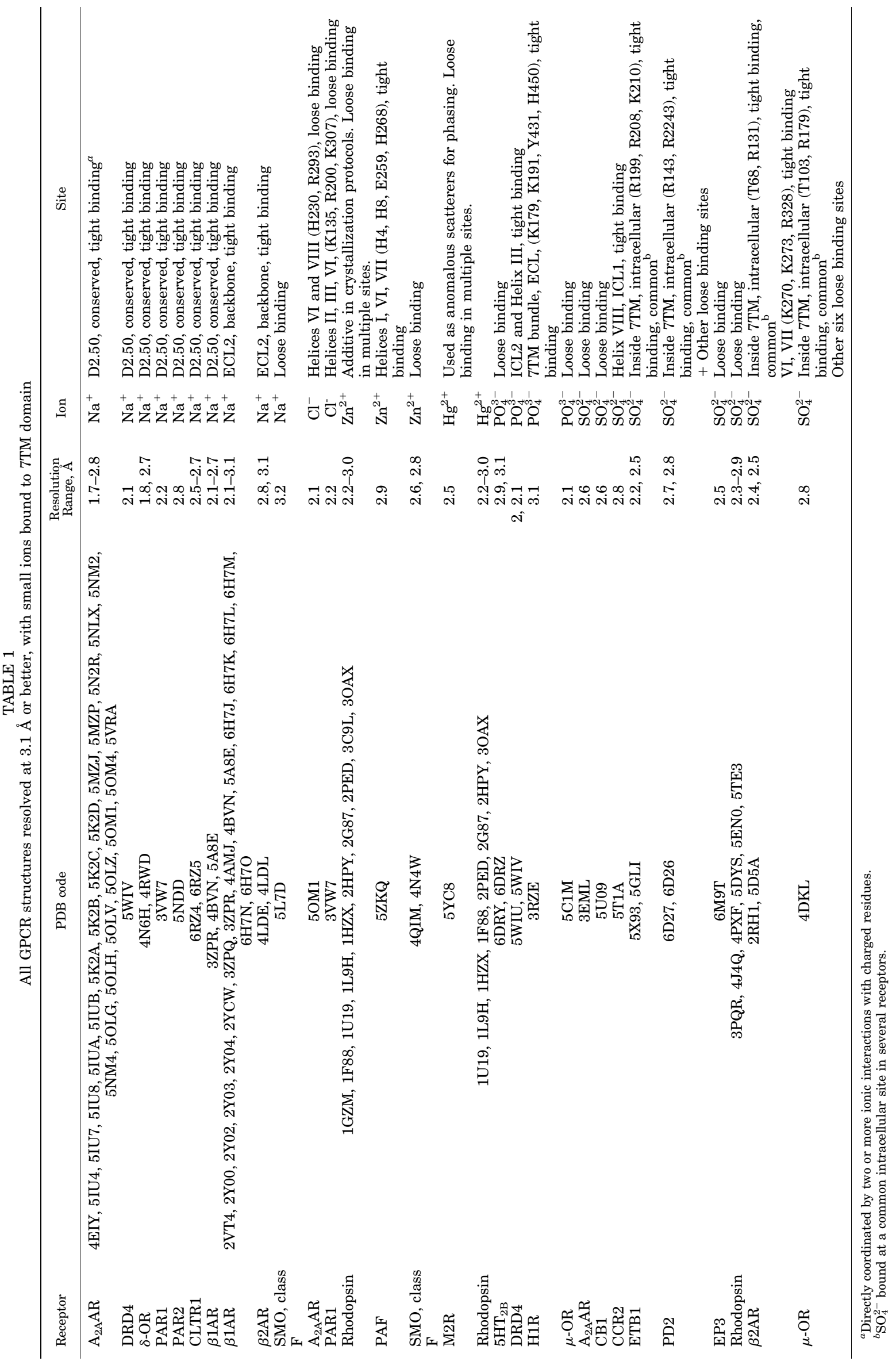


A

A Class B1 genus Class C (22)

B

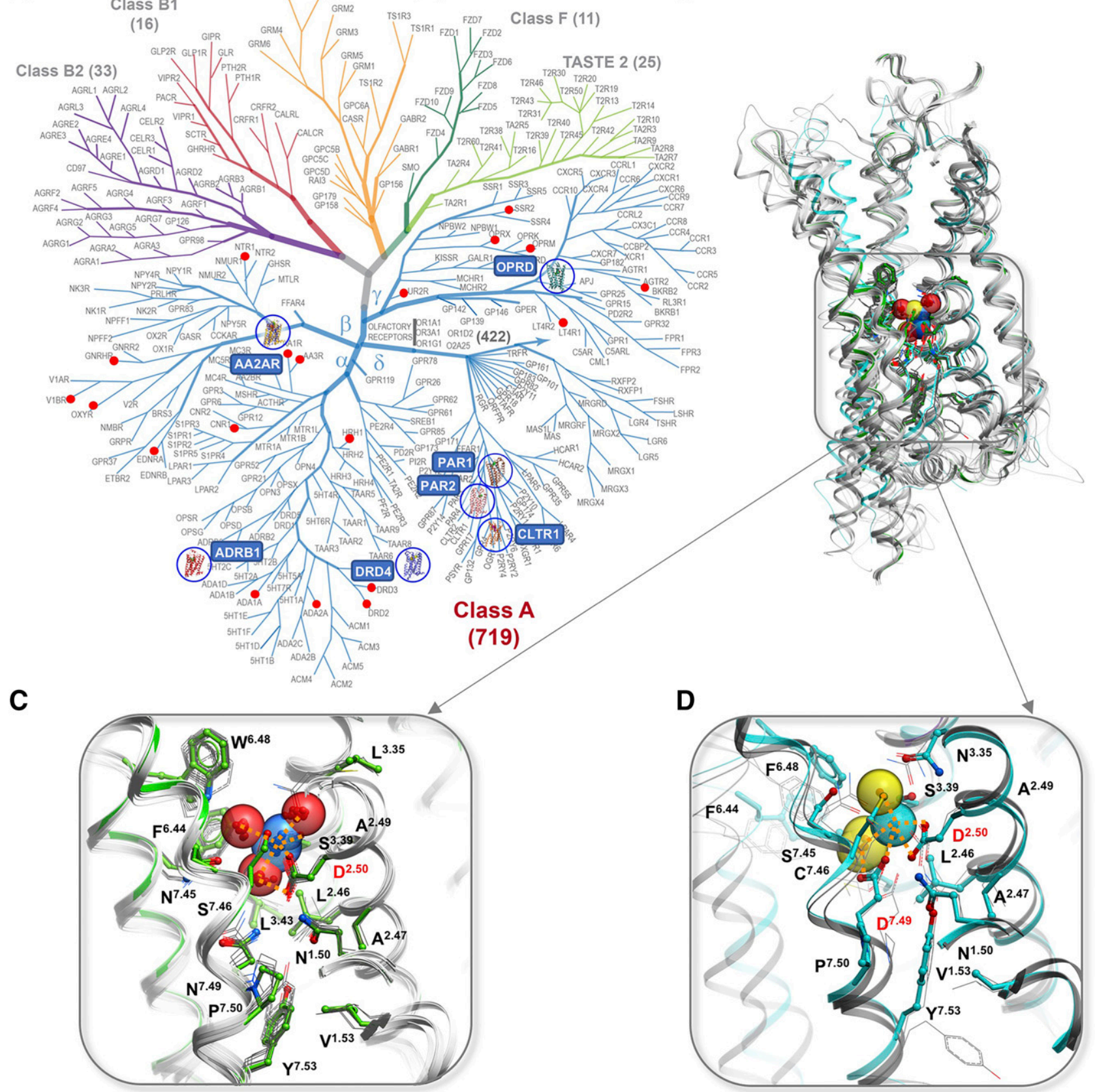

Fig. 2. Conserved $\mathrm{Na}^{+}$sites in GPCRs. (A) GPCR superfamily tree with blue circles highlighting receptor structures with $\mathrm{Na}^{+}$resolved in the conserved pocket and red dots marking GPCR with established allosteric effect of $\mathrm{Na}^{+}$. (B) Overview of the $\mathrm{Na}^{+}$position in $7 \mathrm{TM}$ helical bundle. (C) Type I Na ${ }^{+}$site, first discovered in $\mathrm{A}_{2 \mathrm{~A}} \mathrm{R}$ (green cartoon and sticks) and conserved in majority of Class A GPCRs structures (gray). (D) Distinct coordination of $\mathrm{Na}^{+}$by two acidic residues $\mathrm{D}^{2.50}$ and $\mathrm{D}^{7.49}$ in Type II sodium site as resolved in PAR1 (cyan), PAR2 and CLTR1 (gray) in $\delta$-branch GPCRs.

conserved aspartate residue $\mathrm{D}^{2.50}$ (superscript shows generic numbering of GPCR residues as described in Isberg et al. (2015). Analysis of the structures and sequences of class A GPCRs revealed the highly conserved nature of the sodium pocket, 15 residues of which are conserved exactly in 45 diverse receptors and with minor variations in a vast majority of class A GPCRs families (Fig. 2, C and D) (Katritch et al., 2014). Moreover, those class A receptors that lack the key residues of the sodium site naturally, or via introduced mutations, have their ligand-induced signaling dramatically reduced or completely abolished (Katritch et al., 2014; Massink et al., 2015; White et al., 2018). While our understanding of ion binding sites and their biochemical and physiologic effects on GPCR signaling has greatly expanded in the last few years, we are only beginning to understand the new possibilities for harnessing this knowledge for the discovery of safer and more efficient drugs that have improved subtype and/or functional selectivity (Roth, 2019). 


\section{Structural Data for Conserved and Nonconserved Ion Binding Sites in G-Protein-Coupled Receptors}

\section{A. Conserved Sodium Binding Site in Class A G-Protein-Coupled Receptors}

1. High-Resolution Structures of Sodium in the Conserved Site. Sodium ion in the conserved sodium pocket was first crystallographically identified in the $\mathrm{A}_{2 \mathrm{~A}}$ adenosine receptor (Liu et al., 2012b), quickly followed by PAR1 thrombin (Zhang et al., 2012), $\beta_{1} \mathrm{AR}$ adrenergic (Miller-Gallacher et al., 2014), $\delta$-OR opioid (Fenalti et al., 2014), and D4 dopamine receptors (Wang et al., 2017). Remarkably, despite these structures representing receptors in different major branches of class A GPCRs and having low sequence identity between them (20\%-35\%), the sodiumbinding positions in the structures were found to be almost identical (within 0.5-1.5 $\AA$ ) with all of them anchored at the negatively charged $\mathrm{D}^{2.50}$ side chain. Moreover, the sequence of all 16 residues lining the sodium binding pocket and their conformations in receptor structures are remarkably conserved either in the whole class A GPCR or its individual branches (Table 2). The unprecedented level of conservation of the $\mathrm{Na}^{+}$pocket as a structural feature was also emphasized by the fact that the positions of up to 10 water molecules in the pocket comprising $\mathrm{Na}^{+} /$water cluster were found conserved between such distant receptors as $\mathrm{A}_{2 \mathrm{~A}}, \beta_{1} \mathrm{AR}$, and $\delta$-OR. Such a high level of sequence and structural conservation implied a critical functional role of this $\mathrm{Na}^{+}$site in class A GPCRs (Liu et al., 2012b; Katritch et al., 2014). It is important to note, also, that the sodium pocket lies in close proximity and, in most structures of class A GPCRs, is directly connected to the orthosteric pocket making it potentially accessible to ligand design, as discussed below in section $I V$.

A number of high-resolution structures have been more recently obtained (see Table 1), shedding light on the $\mathrm{Na}^{+}$pocket and revealing new features of the $\mathrm{Na}^{+}$ binding site. Thus, more than 20 additional structures of antagonist-bound complexes for each of the $A_{2 A}$ adenosine and $\beta_{1}$ adrenergic receptors show that the $\mathrm{Na}^{+} /$water cluster can be reliably resolved in GPCR structures at up to about $2.3 \AA$ resolution. Among them, the X-ray free-electron laser crystal structure of $\mathrm{A}_{2 \mathrm{~A}} \mathrm{R}$ (1.96 $\AA$ resolution) is especially important (Batyuk et al., 2016), because it was determined at room temperature. This structure demonstrated that existence of a well-defined conformation of $\mathrm{Na}^{+} /$water in the pocket detected in crystal structures of many GPCRs was not an artifact of cryo-freezing, but rather a result of the unique stability of the cluster itself.

Key insights were obtained from the antagonist-bond dopamine receptor D4 (DRD4) high-resolution structure (Wang et al., 2017), which was determined both with and without sodium. Importantly, an electron density for sodium was observed only when $\mathrm{Na}^{+}$ $(\sim 200 \mathrm{mM})$ was added during crystallization, thus providing the most direct structural evidence for $\mathrm{Na}^{+}$ in its binding site. Remarkably, even though another, the sodium-free structure of DRD4, was slightly higher resolution, the electron densities for water molecules forming the $\mathrm{Na}^{+}$/water cluster disappeared, showing that $\mathrm{Na}^{+}$is critical for the stability of the whole cluster. Indeed, water clusters in polar pockets can usually dynamically form many combinations of their hydrogen bonding network, which compromise detection of individual water molecules. In contrast, the presence of the $\mathrm{Na}^{+}$with a strong ionic bridge to $\mathrm{D}^{2.50}$ creates a specific configuration of the whole cluster, characterized

TABLE 2

Residue conservation in the sodium pocket for different branches of Class A GPCRs.

Numbers show \% conservation, also highlighted by color - from low (white), to medium (yellow), to green (high).

\begin{tabular}{|c|c|c|c|c|c|c|c|c|c|c|c|c|c|c|c|c|}
\hline Position & 1.50 & 1.53 & 2.46 & 2.47 & 2.49 & 2.50 & 3.35 & 3.39 & 3.43 & 6.44 & 6.48 & 7.45 & 7.46 & 7.49 & 7.50 & 7.53 \\
\hline \multirow{5}{*}{$\begin{array}{l}\alpha \text {-branch } \\
(90)\end{array}$} & $\mathrm{N}$ & $\mathrm{V}$ & $\mathrm{L}$ & A & $\mathrm{A} / \mathrm{S} / \mathrm{T}$ & D & $\mathrm{F} / \mathrm{C} / \mathrm{L} / \mathrm{S}$ & $\mathrm{S}$ & $\mathrm{L}$ & $\mathrm{F}$ & $\mathrm{W}$ & $\mathrm{N}$ & $\mathrm{S}$ & N/D & $\mathrm{P}$ & $\mathrm{Y}$ \\
\hline & \multirow[t]{4}{*}{100} & \multirow[t]{4}{*}{83} & \multirow[t]{4}{*}{88} & \multirow[t]{4}{*}{79} & $\begin{array}{l}58 \\
\end{array}$ & \multirow[t]{4}{*}{97} & 26 & \multirow[t]{4}{*}{84} & \multirow[t]{4}{*}{81} & \multirow[t]{4}{*}{89} & \multirow[t]{4}{*}{92} & \multirow[t]{4}{*}{82} & \multirow[t]{4}{*}{77} & 82 & \multirow[t]{4}{*}{93} & \multirow[t]{4}{*}{93} \\
\hline & & & & & 17 & & 20 & & & & & & & 17 & & \\
\hline & & & & & 17 & & 18 & & & & & & & & & \\
\hline & & & & & & & 18 & & & & & & & & & \\
\hline \multirow{3}{*}{$\begin{array}{l}\beta \text {-branch } \\
\text { (38) }\end{array}$} & $\mathrm{N}$ & $\mathrm{V} / \mathrm{L}$ & $\mathrm{L}$ & $\mathrm{A} / \mathrm{S}$ & S/A & D & S & $\mathrm{S} / \mathrm{T}$ & $\mathrm{L}$ & $\mathrm{F} / \mathrm{Y}$ & $\mathrm{W}$ & $\mathrm{N} / \mathrm{S}$ & $\mathrm{S} / \mathrm{T}$ & $\mathrm{N}$ & $\mathrm{P}$ & $\mathrm{Y} / \mathrm{L}$ \\
\hline & \multirow[t]{2}{*}{92} & 47 & \multirow[t]{2}{*}{95} & 76 & 45 & \multirow[t]{2}{*}{92} & \multirow[t]{2}{*}{61} & 71 & \multirow[t]{2}{*}{71} & 76 & \multirow[t]{2}{*}{89} & 47 & 61 & \multirow[t]{2}{*}{87} & \multirow[t]{2}{*}{92} & 74 \\
\hline & & 24 & & 16 & 32 & & & 24 & & 21 & & 42 & 18 & & & 18 \\
\hline \multirow{3}{*}{$\begin{array}{l}\gamma \text {-branch } \\
\text { (65) }\end{array}$} & $\mathrm{N}$ & $\mathrm{V}$ & $\mathrm{L}$ & A & $\mathrm{A} / \mathrm{S}$ & $\mathrm{D}$ & $\mathrm{N} / \mathrm{S}$ & $\mathrm{S} / \mathrm{G}$ & $\mathrm{L} / \mathrm{I}$ & $\mathrm{F}$ & $\mathrm{W}$ & $\mathrm{N} / \mathrm{H}$ & $\mathrm{S} / \mathrm{C}$ & $\mathrm{N}$ & $P$ & Y \\
\hline & \multirow[t]{2}{*}{97} & \multirow[t]{2}{*}{86} & \multirow[t]{2}{*}{97} & \multirow[t]{2}{*}{88} & 71 & \multirow[t]{2}{*}{94} & 61 & 71 & 67 & \multirow[t]{2}{*}{86} & \multirow[t]{2}{*}{88} & 55 & 64 & \multirow[t]{2}{*}{95} & \multirow[t]{2}{*}{97} & 97 \\
\hline & & & & & 23 & & 18 & 17 & 21 & & & 35 & 30 & & & \\
\hline$\delta$-branch & $\mathrm{N}$ & $\mathrm{A} / \mathrm{V}$ & L & A & $\mathrm{A} / \mathrm{S}$ & D & $\mathrm{N}$ & $\mathrm{S} / \mathrm{G}$ & $\mathrm{L}$ & $\mathrm{F}$ & $\mathrm{F}$ & $\mathrm{N}$ & $\mathrm{S} / \mathrm{C}$ & $\mathrm{D} / \mathrm{N}$ & $\mathrm{P}$ & $\mathrm{Y}$ \\
\hline & 98 & 42 & 85 & 57 & 65 & 91 & 52 & 72 & 82 & 62 & 60 & 80 & 49 & 57 & 94 & 94 \\
\hline & & 38 & & & 23 & & & 18 & & & & & 23 & 34 & & \\
\hline
\end{tabular}


by well-defined electron densities, as observed previously in $\mathrm{A}_{2 \mathrm{~A}}, \beta_{1} \mathrm{AR}$, and $\delta$-OR high-resolution structures. It is also worth noting that there was no significant difference in the receptor conformation itself between $\mathrm{Na}^{+}$-bound and sodium-free structures of DRD4, even in the sodium-coordinating pocket residues, suggesting that the presence of sodium ion does not "induce" any specific conformational macrostate of the receptor. Instead, the observed stabilizing role of $\mathrm{Na}^{+}$is manifested in shifting equilibrium toward the same inactive state conformation as observed without sodium.

The recently solved structures of the PAR2 proteinaseactivated receptor (Cheng et al., 2017a) and of the cysteinyl leukotriene receptor CLTR1 (Luginina et al., 2019) further confirm the presence of sodium in the $\delta$-branch of GPCRs as was identified previously for PAR1 (Zhang et al., 2012). These receptors provide a distinct structure of the $\mathrm{Na}^{+}$pocket (Fig. 2D; Table 2), where sodium is coordinated by two acidic residues, $\mathrm{D}^{2.50}$ and $\mathrm{D}^{7.49}$, instead of only $\mathrm{D}^{2.50}$ in most other class A receptors, which have $\mathrm{N}^{7.49}$. This double salt bridge coordination shifts the sodium position about $1.5 \AA$ "down" along the polar channel and changes the overall $\mathrm{Na}^{+}$coordination and conservation pattern compared with "classical" sodium pocket in $\alpha$ - and $\gamma$-branches of GPCRs.

2. Sodium Ion Detection Criteria. While divalent ions in crystal structures are often detected by their anomalous diffraction, monovalent ions including $\mathrm{Na}^{+}$ lack such anomalous diffraction. Reliable detection of monovalent ions like $\mathrm{Na}^{+}$in the protein crystal structures is based on high resolution (usually $<2.3 \AA$ ), the strong electron density in a potential $\mathrm{Na}^{+}$ion position and the unambiguous detection of at least five oxygen (or potentially nitrogen) atoms that comprise the $\mathrm{Na}^{+}$ coordination shell. The sodium ion can be identified then by its 5 -atom coordination geometry and short characteristic distances to the coordinating atoms (2.3-2.5 $\AA$ ), as discussed in Liu et al. (2012b). These criteria help to differentiate $\mathrm{Na}^{+}$from four-atom tetrahedral coordination of water molecules and characteristic water interaction distances (2.8-3.1 $⿱$ A). At even higher resolution, e.g., $<2.0 \AA$, the accuracy of measurement may also be sufficient (Cheng et al., 2017a) to differentiate $\mathrm{Na}^{+}$coordination distances from those of other monovalent ions, e.g., longer distances for $\mathrm{K}^{+}$ $(2.6-2.8 \AA)$ and shorter for $\mathrm{Li}^{+}(1.9-2.1 \AA)$ (Kuppuraj et al., 2009), thus specifically detecting $\mathrm{Na}^{+}$.

It is important to note that the high structural stability of the protein and of the $\mathrm{Na}^{+} /$water cluster is as important for detection of $\mathrm{Na}^{+}$as the resolution of the structures. Thus, it was possible to reliably resolve $\mathrm{Na}^{+}$ in PAR2 even at somewhat lower $2.8 \AA$ resolution, because $\mathrm{Na}^{+}$was coordinated by five oxygen atoms of the protein side chains, including two from the charged carboxy groups of $D^{2.50}$ and $D^{7.49}$. At the same time, in some higher resolution structures, for example $\mathrm{OX}_{2} \mathrm{R}$
(PDB: 5WQC, resolution 1.96 ^), allosteric sodium was apparently absent from the conserved pocket (Suno et al., 2018a). Though some waters of the sodium pocket were resolved, the density for sodium and a neighboring position interacting with $\mathrm{D}^{2.50}$ were not well defined, precluding $\mathrm{Na}^{+}$detection. This is not surprising, as the $\mathrm{Na}^{+}$concentration used for this crystallization was $120 \mathrm{mM}$, which is in the range close to $\mathrm{EC}_{50}$ of $\mathrm{Na}^{+}$in some receptors (e.g., $\sim 100 \mathrm{mM}$ for DRD4), and thus may not allow the full saturation required for $\mathrm{Na}^{+}$/water cluster stability and detection. Therefore, the lack of sodium density in this structure does not necessarily mean that the fully conserved $\mathrm{Na}^{+}$pocket in OX2R does not bind sodium, but rather that it could not be detected crystallographically under the conditions used. Further studies of $\mathrm{Na}^{+}$in OX2R, including validation of the classic $\mathrm{Na}^{+}$effect on agonist binding, may be needed to answer this question more definitively (Suno et al., 2018a).

All structures with bound $\mathrm{Na}^{+}$so far were resolved by crystallography, although it is possible that structural information about sodium pocket may also come in the future from cryo-EM studies. The best GPCR structures by cryo-EM have been solved at $\sim 3.0 \AA$ resolution (Zhao et al., 2019), but the rapid progress in the cryo-EM field and detection of soluble protein structures at resolutions as high as $1.8 \AA$ (Merk et al., 2016) suggests that this crystal-free technology may ultimately allow deciphering the sodium cluster and other ion binding details as well.

3. Lower Resolution Inactive State Structures of Class A Compatible with Sodium Ion Binding. In many other crystal structures of diverse class A GPCRs where the modest resolution $(2.4-2.9 \AA)$ was insufficient reliably to resolve sodium ion, the conserved pocket is still fully compatible with sodium presence in the structure.

- In the $\alpha$-branch of class A GPCRs, this includes $\mathrm{A}_{1}$ adenosine (Cheng et al., 2017b) and most of the aminergic GPCR structures, for example, $\beta_{2} \mathrm{AR}$ (2RH1), D3R (3PBL) that have closely related subtypes with $\mathrm{Na}^{+}$explicitly determined crystallographically.

- In the $\gamma$-branch, where sodium was only resolved in high-resolution structure of delta opioid receptor (DOR) so far (Fenalti et al., 2014), the pockets are fully conserved and compatible with $\mathrm{Na}^{+}$binding in structures of all other opioid receptors including mu (MOR) (Manglik et al., 2012), kappa (KOR) (Wu et al., 2012) and nociceptin (NOP) (Thompson et al., 2012) opioid receptors.

- In the $\beta$-branch, the NTSR1 neurotensin receptor was previously characterized as having a sodium binding site (White et al., 2012; Krumm et al., 2015), although $\mathrm{Na}^{+}$was not crystallographically resolved in the NTSR1-agonist complex as it 
represented a partially active-like state. An interesting observation was made recently for another $\beta$-branch GPCR, the $\mathrm{ET}_{\mathrm{B}}$ endothelin receptor (Shihoya et al., 2017). Though a weak allosteric sodium effect was detected in the $\mathrm{ET}_{\mathrm{B}}$ receptor, it was above the physiologic sodium concentration $(>1 \mathrm{M})$, probably owing it to the fact that one of the key residues of the otherwise conserved sodium pocket, $\mathrm{Y}^{7.53}$, was replaced by $\mathrm{L}^{7.53}$ in the $\mathrm{ET}_{\mathrm{B}}$ receptor. Correspondingly, the crystal structure of $\mathrm{ET}_{\mathrm{B}}$ solved at relatively high resolution $2.2 \AA$ had the cavity filled with electron densities that were more compatible with water molecules than with sodium. Intriguingly, the closely related $\mathrm{ET}_{\mathrm{A}}$ has much stronger $\mathrm{Na}^{+}$binding at $\mathrm{EC}_{50}=245$ $\mathrm{mM}$, and a high-resolution $\mathrm{ET}_{\mathrm{A}}$ structure might provide new insights for this family.

4. Structures of Active State G-Protein-Coupled Receptors Are Incompatible with Sodium Binding. Comparison of the sodium pocket conformation in inactive- and active-state structures of $\mathrm{A}_{2 \mathrm{~A}}, \beta_{1} \mathrm{AR}$, muscarinic, 5-HT, and opioid receptors (Fig. 3) reveals that the sodium pocket shape, conformation, and interaction network change dramatically upon activation, resulting in a partially collapsed pocket that is not compatible with high-affinity binding of sodium (Katritch et al., 2014). In general, active state conformations are characterized by an inward movement of the TM7 backbone, which directly clashes with the sodium site and rearranges sodium-coordinating side chains so that they form direct hydrogen bonds instead of $\mathrm{Na}^{+}$mediated (e.g., between $\mathrm{D}^{2.50}$ and $\mathrm{S}^{3.39}$ ) that preclude sodium coordination (Fig. 3C). Other major activation related changes, like the outward movement of TM6, also change the shape of the $\mathrm{Na}^{+}$pocket and disrupt the so-called hydrophobic layer (Yuan et al., 2014). Disruption of the hydrophobic layer, comprising residues 1.53, $2.46,3.43,7.53$ at the bottom of the $\mathrm{Na}^{+}$pocket, opens the floodgate for water and sodium ion egress toward the intracellular side.

Such conformational changes in active-like states were described recently for NTSR1 (White et al., 2012; Krumm et al., 2015) and AT2R (Zhang et al., 2015b, 2017) in structures of complexes with agonists, as well as the structures of fully active MOR (PDB: 5C1M) (Huang et al., 2015a) and KOR (PDB: 6B73) (Che et al., 2018) bond to both agonists and nanobodies. The MOR structure is especially important in this respect because
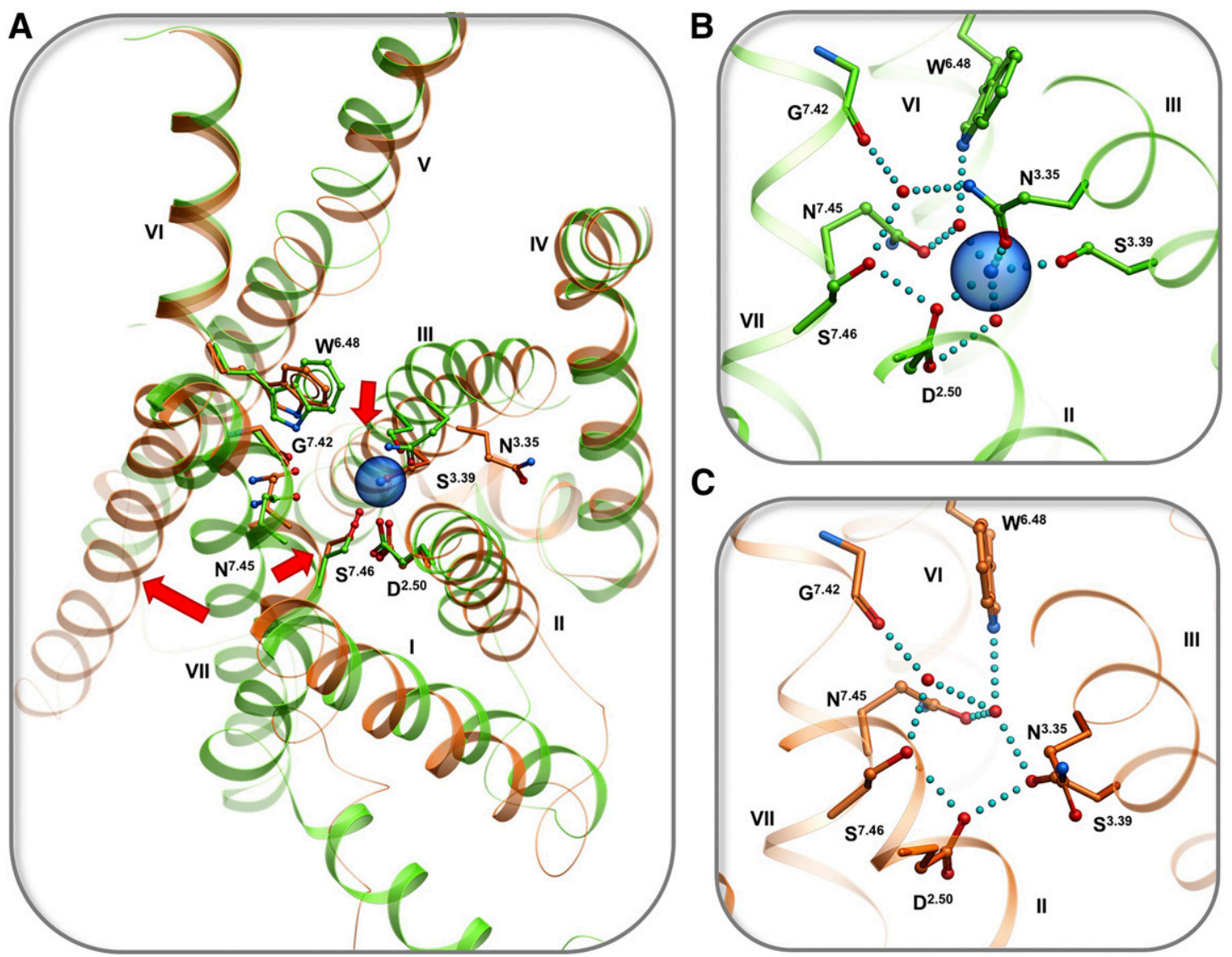

Fig. 3. Conformational changes in the sodium pocket upon activation of opioid receptors. (A) Superimposition of high-resolution structures of $\delta$-opioid receptor in inactive state (green, PDB: $4 \mathrm{~N} 6 \mathrm{H}$, resolution $1.8 \AA$ ) and $\mu$-opioid receptor in active state (orange, PDB: $5 \mathrm{C} 1 \mathrm{M}$, resolution $2.1 \AA$ ); conformational changes shown by arrows. (B) Close up of sodium pocket in inactive state. (C) Close up of the pocket in active state. Hydrogen bonds and salt bridges are shown by cyan dotted lines. 
it was solved at a high $2.1 \AA$ resolution. A detailed examination of the pocket structure reveals no electron density suitable for $\mathrm{Na}^{+}$, and in general, the active state conformation is incompatible with $\mathrm{Na}^{+}$binding (Huang et al., 2015a).

It should be noted, that while the described above general conformational rearrangements are common to active state conformations, the details of newly formed interactions in the pocket can differ between the structures quite dramatically. This contrasts with the very conserved conformation of the residues in the structures of inactive GPCRs. This loss of uniformity can be explained by natural differences in the pocket between receptors, but also by different activation states (intermediate activated to fully active) and a range crystallographic resolution (from 2.1 to $3.5 \AA$ ) (Katritch et al., 2014).

5. Allosteric Ligands can Block Sodium Binding. Although the $\mathrm{Na}^{+}$pocket is small, $\sim 200 \AA^{3}$ as estimated in $\mathrm{A}_{2 \mathrm{~A}}$ (Liu et al., 2012b), it can bind small molecules like amiloride and its analogs, which have a common positively charged moiety connected to an aromatic ring (Fig. 4) (Liu et al., 2012b; Katritch et al., 2014). The allosteric binding of amiloride has been shown biochemically for several receptors, revealing direct competition with $\mathrm{Na}^{+}$binding and a strong dependence on mutations in $\mathrm{D}^{2.50}$ and other pocket residues (Howard et al., 1987; Gao and Ijzerman, 2000; Gao et al., 2003a,b; Heitman et al., 2008; Gutiérrez-de-Terán et al., 2013; Massink et al., 2015) (Fig. 4B). Crystallographic observation of ligand binding in the $\mathrm{Na}^{+}$pocket has been elusive, until recently the structure of leukotriene B4 receptor BLT1 was solved in complex with a ligand reaching into $\mathrm{Na}^{+}$pocket (Hori et al., 2018). The bitopic ligand BIIL260, spanning the orthosteric pocket and reaching all the way to the sodium binding anchor $\mathrm{D}^{2.50}$, was characterized as an inverse agonist. This is an expected functional effect, as the ligand blocks the sodium site and precludes conformational rearrangements in the pocket, which are required for activation. The bitopic ligand comprised an orthosteric BTL1 selective moiety and a positively charged benzamidine group that forms a salt bridge to $\mathrm{D}^{2.50}$ in a manner similar to amiloride. Interestingly, the study also shows the benzamidine itself has a negative allosteric effect of on BLT1 activation with $K_{\mathrm{B}} \sim 500 \mu \mathrm{M}$, which is much weaker than $K_{\mathrm{B}}$ values reported for amilorides (Fig. 4B). This allosteric effect of benzamidine was also confirmed in the $\beta_{2} \mathrm{AR}$, suggesting its potential effect in many other class A GPCRs with a similar $\mathrm{Na}^{+}$pocket structure. A combination of orthosteric selectivity with a controlled allosteric sodium pocket functionality in bitopic ligands was suggested as a beneficial path for drug discovery, as discussed in section $I V$ below.

6. Mutations Abolishing Sodium Binding. A central role of the $\mathrm{Na}^{+}$site in activation-related conformational changes suggests that mutation in this site can modulate the stability of specific functional states. Moreover, by removing $\mathrm{Na}^{+}$as a key "gear" in the transmission mechanism, the conformational space sampled by the receptor along the activation path is modified and can improve the thermostability of the receptor (Katritch et al., 2014). Indeed, several structures of GPCRs have been recently obtained with mutations in the sodium pocket that improved receptor thermostability.

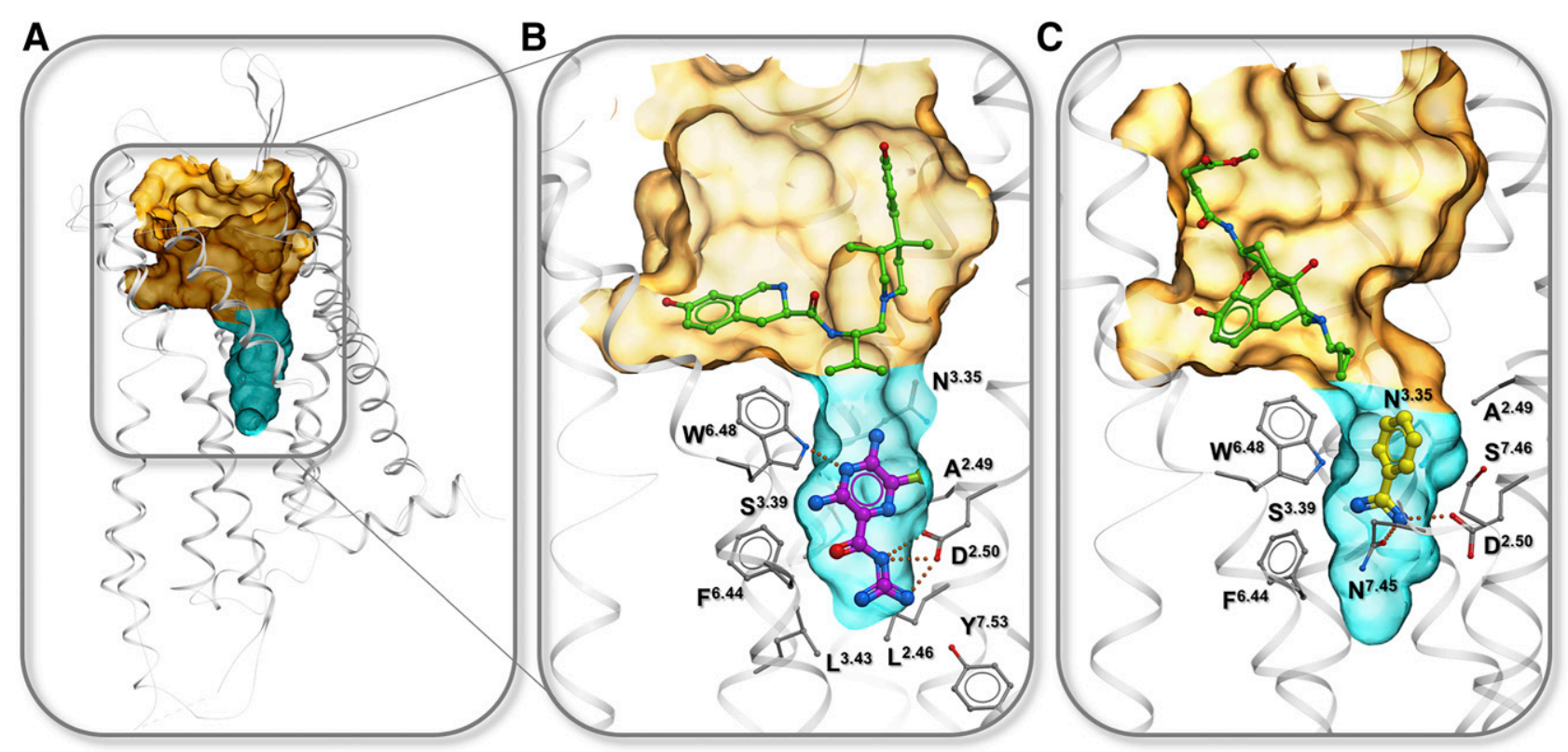

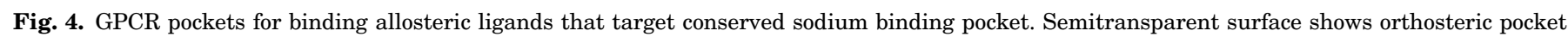

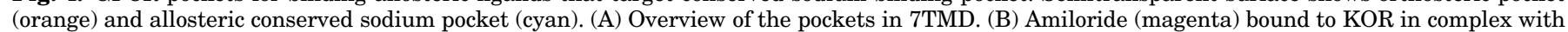

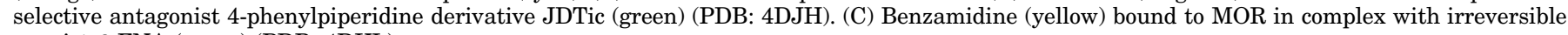
agonist $\beta$-FNA (green) (PDB: 4DKL). 
Specifically, a mutation in the $\mathrm{Na}^{+}$anchor residue $\mathrm{D}^{7.49} \mathrm{~N}$ helped to crystallize and solve structures of P2Y1 receptor in complex with antagonists (PDB: 4XNV) (Zhang et al., 2015a), as well as P2Y12 complex with agonist (PDB: 4PXZ) (Zhang et al., 2014). Some of the established sodium-disrupting mutations $\left(\mathrm{D}^{2.50} \mathrm{~N}\right.$, $\mathrm{S}^{3.39} \mathrm{~A}$, and $\mathrm{D}^{7.49} \mathrm{~N}$ ) were included as knowledge-based transferrable mutations in the GPCR thermostabilization algorithm (Popov et al., 2018, 2019). Other mutations in the pocket show promise, e.g., introducing Arg in 3.39 position was theoretically predicted as stabilizing mutation (Yasuda et al., 2017) expected to block the $\mathrm{Na}^{+}$pocket. This mutation recently helped to solve new structures of muscarinic acetylcholine receptor 2 (M2R) (Suno et al., 2018b) and EP4 prostaglandin receptor (Toyoda et al., 2019) in the inactive state.

Because stabilization by sodium pocket destruction usually comes at the expense of losing function, i.e., signaling response to agonists, we specifically studied the structural consequences of some of these mutations in a well-established system such as $\mathrm{A}_{2 \mathrm{~A}}$ adenosine receptor $\left(\mathrm{A}_{\mathrm{A} 2} \mathrm{AR}\right)$ (White et al., 2018). Mutations in sodium-coordinating positions $\mathrm{D}^{2.50} \mathrm{~N}$ and $\mathrm{S}^{3.39} \mathrm{~A}$ were introduced in $\mathrm{A}_{2 \mathrm{~A}} \mathrm{R}$ and assessed both functionally and structurally. This study demonstrated robust improvement in thermostability for the $\mathrm{D}^{2.50} \mathrm{~N}$ mutation in the apo-, agonist-, and antagonist-bound receptor, supporting its broad importance. Although $\mathrm{D}^{2.50} \mathrm{~N}$ resulted in complete disruption of G-protein signaling mechanism, it retained a full affinity for antagonists, while even improving binding of agonist, as expected for GPCRs with decoupling mutations. Importantly, the crystal structures of $\mathrm{A}_{2 \mathrm{~A}} \mathrm{R} \mathrm{D}^{2.50} \mathrm{~N}$ and $\mathrm{S}^{3.39} \mathrm{~A}$ mutants in complex with agonist UK432097 were conformationally undistinguishable from the wildtype receptor in the same complex, with only minor local variations in the two to three residues directly interacting with the mutation site. This structural resilience to stabilizing mutations in the sodium pocket again suggests that such mutants can be used to facilitate GPCR crystallization (or improved cryo-EM resolution) with minimal disturbance to the resulting overall structure of the receptor.

\section{B. G-Protein-Coupled Receptors that Lack the Conserved Sodium Site}

1. Some Class A G-Protein-Coupled Receptors Lack Specific Sodium Site. A limited number of class A GPCRs lack the key polar residues in the sodium pocket and are apparently not suitable for the selective high-affinity binding of sodium. We estimated about $10 \%-30 \%$ of class A GPCRs lack specific $\mathrm{Na}^{+}$binding in the conserved pocket, depending on the $\mathrm{Na}^{+}$affinity cutoff. The most obvious 36 exceptions are listed in Supplemental Table S1 of our previous review (Katritch et al., 2014), including 1) visual rhodopsin and other opsins that lack conservation in the polar pocket,
2) GPCRs lacking $D^{2.50}$ anchor that are known to lack ligand-induced signaling, some constitutively activated and some acting via dimerization with signaling subtype, 3) some orphan and "putative" GPCR lacking $D^{2.50}$ anchor where ligand signaling has not been established, or 4) receptors where lack of $D^{2.50}$ anchor may be compensated by acidic Asp and Glu in positions 7.49 or 3.39 of the sodium pocket.

Several other interesting cases of receptors with rare deviations in the pocket, which result in dramatically reduced or abolished $\mathrm{Na}^{+}$binding affinity have been studied more recently. Thus, in the NK1 neurokinin receptor (NK1R), the rare $\mathrm{E}^{2.50}$ carboxylic acid side chain, which is longer than the common $\mathrm{D}^{2.50}$, was predicted to occupy the sodium position in this site and make direct interactions with conserved $\mathrm{S}^{3.39}$, $\mathrm{T}^{7.46}$, and $\mathrm{N}^{7.49}$ (Valentin-Hansen et al., 2015). This modeling prediction was recently confirmed by a $2.2 \AA$ resolution structure of NK1R (Schöppe et al., 2019), which also shows that while $\mathrm{E}^{2.50}$ replaces $\mathrm{Na}^{+}$in the site, the structure of water molecules in the pocket is remarkably conserved as in $\mathrm{Na}^{+}$/water cluster resolved in other GPCRs. It was hypothesized that by replacing mobile $\mathrm{Na}^{+}$with direct and immobile carboxy side chain interactions of $\mathrm{E}^{2.50}$, the receptor more tightly controls its basal signaling; indeed NK1R lacks appreciable basal activity. Intriguingly, while NK1R lacks $\mathrm{Na}^{+}$ binding and allosteric effects, both can be restored in the NK1R receptor by "reintroducing" $\mathrm{D}^{2.50}$, as it is in other two NK receptors, NK2 and NK3 (Schöppe et al., 2019). The $\mathrm{E}^{2.50} \mathrm{D}$ and other mutations in the $\mathrm{Na}^{+}$pocket of NK1R also dramatically change the constitutive and biased signaling profile of NK1R, suggesting that evolution uses deviations from the canonical $\mathrm{Na}^{+}$site as a way to modulate the functional properties of receptors.

Interestingly, another rare substitution of a small to larger side chain in 7.46 position of the pocket, e.g., $\mathrm{S}(\mathrm{T}, \mathrm{A})^{7.46} \mathrm{~N}$, is found in only two class A GPCRs including angiotensin AT1 receptor. Assessment of the sodium pocket structure of AT1R, including inactive (Zhang et al., 2015b, 2017) and active-like state (Wingler et al., 2019) structures, suggests that $\mathrm{N}^{7.46}$ side chain and its hydrogen bond interactions with $\mathrm{N}^{3.35}$ may interfere with sodium binding, replacing sodium as a conformational stabilizer and making the receptor insensitive to sodium concentration.

Another example of a GPCR structure with deviations in the sodium pocket incompatible with selective $\mathrm{Na}^{+}$binding is the CCR5 chemokine receptor (CCR5R), which lacks two key sodium coordinating side chains in $\mathrm{N}^{3.35}$ and $\mathrm{S}^{3.39}$ positions, which are replaced by Gly instead. Indeed, while the inactive state structure of CCR5R in complex with an antagonist was solved at relatively high $(2.2 \AA)$ resolution, no density for $\mathrm{Na}^{+}$binding was detected (PDB: 5UIW) (Zheng et al., 2017). The structural deviations in the allosteric pocket 
that compromise $\mathrm{Na}^{+}$binding appear to be common to a group of other inflammatory chemokine receptors, suggesting that the switch in $\mathrm{Na}^{+}$pocket played a key evolutionary role in differentiating the chemokine receptor family into homeostatic (CXCR4-like) and inflammatory (CCR5-like) (Taddese et al., 2018) (see more discussion in section V.C). In general, establishing an accurate structure-activity relationship for the $\mathrm{Na}^{+}$ pockets of all class A GPCRs is far from finished and will require a combination of computational modeling and experimental efforts.

2. Non-Class A G-Protein-Coupled Receptors Lack Conserved Sodium Sites in 7-Transmembrane Domains. Potential ion binding sites have been identified or proposed for non-class A GPCRs, both in their 7TM domains and soluble extracellular domains; however, they are structurally distinct from the conserved class A GPCR $\mathrm{Na}^{+}$site and appear to have different functional and evolutionary roles. In the class B 7TM domain, an allosteric $\mathrm{Na}^{+}$site was proposed by MD simulations in the glucagon receptor, with the ion coordinated by residues Glu362 $2^{6.53 \mathrm{~b}}$, Asn238 $3.43 \mathrm{~b}$, Tyr239 $9^{3.44 \mathrm{~b}}$, and Tyr $400^{7.53 b}$, although the predicted ion residence time in the binding site was very short (Selvam et al., 2018). Moreover, the site is conserved only in four class B receptors that have the key acidic Glu residue in $6.53 \mathrm{~b}$ position, and the biologic significance of ion binding to class B GPCRs remains unclear. None of the class B structures have ions detected in their crystal structures that bind their 7TM or extracellular domains, even though many of the extracellular structures were solved at sub $2.0 \AA$ resolution.

In Class C GPCRs, the internal cavity extends deep in the 7TM bundle reaching approximately the location of the class $\mathrm{A} \mathrm{Na}^{+}$site. There are polar residues like $\mathrm{Y} 659^{3.40 \mathrm{c}}$, T781 ${ }^{6.44 \mathrm{c}}$, and $\mathrm{S} 809^{7.45 \mathrm{c}}$ in this region that create a hydrophilic subpocket, and indeed a water molecule has been resolved in this position in the mGLuR5 metabotropic glutamate receptor structure (mGluR5) solved at $2.2 \AA$ resolution (PDB: 6FFI) (Christopher et al., 2019). This polar triad is conserved in seven of eight $m$ GLuR receptors (but not other class C), suggesting some role for a water binding site. However, the subpocket lacks any acidic residues compatible with specific binding of cations like $\mathrm{Na}^{+}$. None of the currently available class $\mathrm{C}$ structures have an ion resolved crystallographically, even at $2.2 \AA$ resolution.

Similarly, in class F GPCRs, exemplified by the smoothened receptor structures (Wang et al., 2013) and the recently solved structure of apo FZD4 receptor (Yang et al., 2018), there is an extended polar channel in the 7TM domain, with water molecules coordinated by the conserved in class $\mathrm{F}$ residues Y262 $2.52 \mathrm{a}, \mathrm{S} 317^{3.40 \mathrm{a}}$, and Y444 ${ }^{6.41 \mathrm{a}}$. Again, none of the residues in the core of the 7TM has an acidic side chain, precluding specific ion binding in this region.
Some nonspecific binding ions have been detected in smoothened receptor (SMO) structures, though they are not likely to play a substantial functional role in these receptors.

\section{Nonconserved Ion Binding Sites in G-Protein- Coupled Receptors}

Sodium ions, as well as other single and polyatomic ions have been found in many crystal structures of GPCRs with sufficient resolution, as listed in Table 1. Thus, for the $\beta_{1} \mathrm{AR}$ and $\beta_{2} \mathrm{AR}$, in addition to the conserved sodium site, a second $\mathrm{Na}^{+}$ion was also identified in the ECL2, coordinated by three carboxy groups of the protein backbone and 2 water molecules. This tightly bound $\mathrm{Na}^{+}$, along with a disulfide bond formed by cysteines of the loop, apparently helps to stabilize the $\alpha$-helix-loop structural motif in the ECL2 of these receptors, and thus apparently serves a structural role. This particular sequence and structural motif, however, can be found in only three receptors of $\beta$-AR subfamily and is not conserved in other GPCRs.

Other notable nonconserved sites include phosphate ion $\mathrm{PO}^{3-}$ in the ECL region of the $\mathrm{H} 1$ histamine (H1R) receptor (Shimamura et al., 2011). As described in this H1R structural paper, the $\mathrm{PO}^{3-}$ ion plays an important role in binding and selectivity of some of the ligands (see more discussion in section IV.C), but this site is unique for H1R.

Specific binding of $\mathrm{Zn}^{2+}$ has also been observed in the of PAF1 platelet activating receptor receptor extracellular loops tightly coordinated by three His and one Glu side chains with distances as low as 2.0-2.2 $\AA$ (Cao et al., 2018). This can explain $\mathrm{Zn}^{2+}$ induced inhibition of platelet activating factor binding to the receptor and physiologic reduction information of platelets (Nunez et al., 1989). Ions have been described as endogenous ligands to some of the GPCRs. Thus, $\mathrm{Ca}^{2+}$ ion is an endogenous agonist for eponymous CaSR calcium-sensing receptor (Chang et al., 2008; Hannan et al., 2018). CaSR is critical for many of the functions dependent upon the regulation of $\mathrm{Ca}^{2+}$ metabolism, including the parathyroid gland and bone development. The allosteric modulation by extracellular calcium has been studied extensively for another Class C GPCR family, the metabotropic glutamate receptors, where the $\mathrm{Ca}^{2+}$ site adjacent to the Glu site was predicted and biochemically characterized (Jiang et al., 2010, 2014). Most recently, $\mathrm{Ca}^{2+}$ was also revealed as an important allosteric modulator of Class B parathyroid hormone receptor signaling, and the structural determinants of the ion binding were proposed (White et al., 2019). Also, $\mathrm{Zn}^{2+}$ has been described as an endogenous agonist for the GPR39 receptor, for which the activation site and mechanism have been proposed (Storjohann et al., 2008; Sato et al., 2016). It would be very interesting to test these hypotheses to gain a better understanding of the atomistic mechanisms when the high-resolution structures of these receptors are available. 


\section{Nonspecific Ion Binding in Crystal Structures}

Multiple ions have been found crystallographically in the intracellular region of the receptor (Fig. 1; Table 1); however, most of them have loose interactions with the receptor, suggesting nonspecific binding. As the intracellular region is enriched with positively charged Arg and Lys residues, it is not surprising that all of the ions identified in this region are anions, including $\mathrm{Cl}^{-}, \mathrm{PO}^{3-}$, and $\mathrm{SO}^{2-}{ }^{2-}$. In most cases, the ions are coordinated by one or two positively charged side chains, although in general, the binding is rather loose and the ions remain highly exposed to solvent. Note also that these intracellular ion binding sites are not reproduced between receptors and, in most cases, not even between different subunits and different structures of the same receptor, so this binding is probably nonspecific and only identified due to the high concentration of these ions in crystallization conditions.

Some divalent cations like $\mathrm{Zn}^{2+}$ and $\mathrm{Hg}^{2+}$ have been also detected bound at the lipid interface of the 7TM bundle. Interestingly, in almost all these cases these metal cations have been found in structures of rhodopsin, reflecting specific crystallization conditions that used a high concentration of the ions. One other crystal structure with $\mathrm{Hg}^{2+}$ is a M2 muscarinic receptor structure (Suno et al., 2018b), where the ions are bound on the lipid interface of the 7TM domain and do not make any ionic or even substantial polar contacts, making their binding apparently nonspecific.

Many other ions present in high concentrations in crystallographic conditions are likely to be loosely and nonspecifically bound in GPCRs, but were not identified in crystal structures because they lack well-defined electron density. Their physiologic role is usually limited to nonspecific ionic strength effects at high concentrations. For example, some studies report a component of the $\mathrm{Na}^{+}$allosteric effects that are independent of $\mathrm{D}^{2.50}$ mutation in H1R (Hishinuma et al., 2017). This is not surprising, given numerous charged residues in GPCRs, often in the orthosteric ligand binding pockets, for example, negative anchor residues in all aminergic opioid and positive phosphate binding residues in $\mathrm{P} 2 \mathrm{Y}$ purinergic receptors. Nonspecific ion binding in ICL3 region may also directly modulate downstream effector binding and activation. Although most of these effects, including the overall ionic strength of the solvent, can manifest themselves only at high concentration of ions and unlikely involved in GPCR function, they need to be accounted in experiments by using appropriate controls.

\section{Functional Role-Why is Sodium So Special for Class A G-Protein-Coupled Receptors?}

Sodium is one of the most abundant ions in the human body, essential for cell energetics, homeostasis, neural function, and many other physiologic functions.
However, our understanding of $\mathrm{Na}^{+}$and its role in the physiologic processes involving GPCR signaling is only now starting to unfold.

\section{A. Allosteric Effects of Sodium on Agonist Binding}

1. "Classical" Allosteric Effect of Sodium Ion on Agonist Binding. As mentioned above, the selective sodium effect was originally discovered in opioid receptors as a negative allosteric modulation of (NAM) of agonist binding upon increasing sodium concentration (Pert et al., 1973; Pert and Snyder, 1974; Simon and Groth, 1975; Roth et al., 1981). This NAM effect in the $\mu$-opioid receptor ( $\mu$-OR) correlated well with ligand efficacy, and for some time was the primary method for differentiating agonists from antagonists; for the latter, the effect was usually neutral or reversed (Pert and Snyder, 1974). This allosteric effect was observed for sodium within the physiologic concentration range of $\sim 140 \mathrm{mM}$, and, in some cases, titration of the effect with sodium concentration allowed measurement of $K_{\mathrm{B}}$ or $\mathrm{EC}_{50}$ values as a proxy for $\mathrm{Na}^{+}$binding affinity. Importantly, the described above NAM effect on agonists was found specific for $\mathrm{Na}^{+}$, while showing much less magnitude for $\mathrm{Li}^{+}$and lacking for $\mathrm{K}^{+}$and larger monovalent cations (Pert and Snyder, 1974). The divalent cations like $\mathrm{Mn}^{2+}, \mathrm{Mg}^{2+}$, and $\mathrm{Ca}^{2+}$ displayed the opposite effect on agonist binding, although the effect was not specific (Pasternak et al., 1975). Since then, studies for numerous other class A GPCRs have demonstrated similar sodium allosteric effect on ligand binding, many of these studies also showing the specificity of $\mathrm{Na}^{+}$binding by mutations in the pocket and corresponding effects on signaling (for historical data see Table 1 in Katritch et al., 2014).

In the years since the structural detection of $\mathrm{Na}^{+}$in the highly conserved GPCR site, a resurgence of interest led to further validation and more detailed biochemical characterization of the sodium allosteric effects in these and many other class A GPCRs (Table 3). Thus, for adenosine $\mathrm{A}_{2 \mathrm{~A}}$ receptor titration of the NAM effect of $\mathrm{Na}^{+}$on agonist NECA allowed estimation of its $\mathrm{IC}_{50}$ value at $44 \pm 6 \mathrm{mM}$ (Massink et al., 2015; White et al., 2018), while confirming the positive allosteric modulation (PAM) effect on antagonist ZM241385 (4(2-(7-amino-2-(furan-2-yl)-[1,2,4] triazolo[1,5-a][1,3,5]triazin5-ylamino)ethyl)phenol). The NAM effect was drastically reduced by $\mathrm{S}^{3.39} \mathrm{~A}$ and $\mathrm{W}^{6.48} \mathrm{~A}$ mutations and completely abolished by $\mathrm{D}^{2.50} \mathrm{~A}, \mathrm{~N}^{7.45} \mathrm{~A}$, and $\mathrm{N}^{7.49} \mathrm{~A}$ mutations in the $\mathrm{Na}^{+}$pocket.

For dopamine receptors, NAM modulation of agonist binding by $\mathrm{Na}^{+}$was confirmed for the D4, D2, and D3 dopamine receptors (Michino et al., 2015; Wang et al., 2017), and titration of the effect on $\mathrm{Na}^{+}$concentration made it possible systematically to compare $\mathrm{Na}^{+}$ affinities for several receptors. Thus, $\mathrm{Na}^{+}$showed lower affinities to dopamine receptors, $K_{\mathrm{B}} \sim 100 \mathrm{mM}$ (D4), $K_{\mathrm{B}} \sim 123 \mathrm{mM}$ (D2), and $K_{\mathrm{B}} \sim 76 \mathrm{mM}$ (D3) compared 


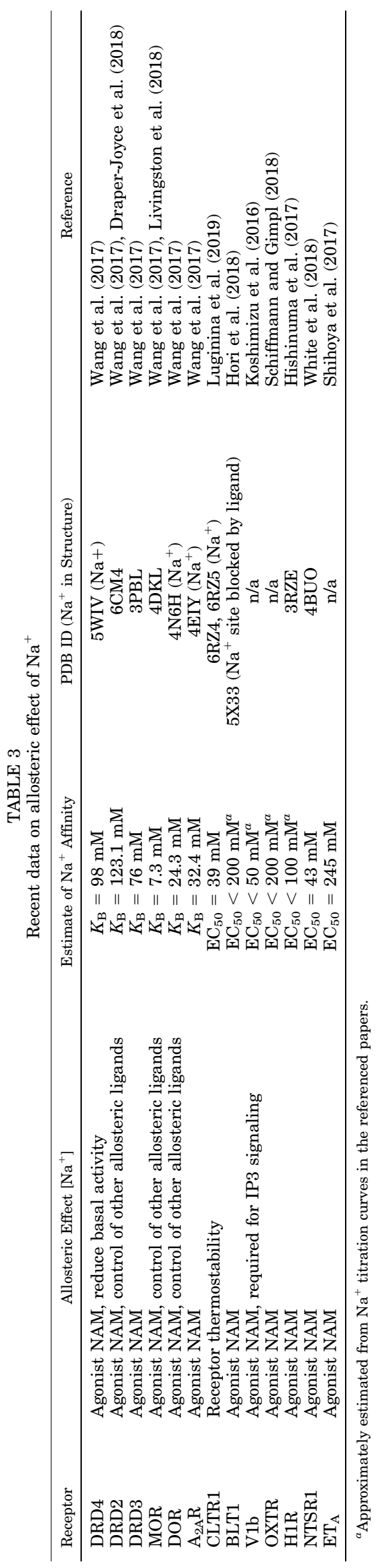

with $K_{\mathrm{B}}$ as high as $7.3 \mathrm{mM}$ for MOR, $24.3 \mathrm{mM}$ for DOR, and $32.4 \mathrm{mM}$ for $\mathrm{A}_{2 \mathrm{~A}}$. As expected (see functional effect in Section B.1), constitutive activity of the $\mathrm{D} 4$ receptor significantly increased at low concentrations of $\mathrm{Na}^{+}$, the effect of which can be blocked by the addition of antagonists (Wang et al., 2017).

For the BLT1 leukotriene receptor, structural studies (Hori et al., 2018) were complemented by biochemical assays that revealed a pronounced negative allosteric effect of $\mathrm{Na}^{+}$on agonist leukotriene B4 binding. Interestingly, the study also described similar effects for an allosteric small molecule benzamide that competes with $\mathrm{Na}^{+}$for the sodium pocket binding.

For V1b vasopressin receptors in cell-based assays, a recent study shows that reducing the concentration of external $\mathrm{Na}^{+}$to below $50 \mathrm{mM}$ dramatically increased cell surface binding of radiolabeled agonist $\left[{ }^{3} \mathrm{H}\right]$ arginine vasopressin (Koshimizu et al., 2016). Interestingly, though agonist binding was increased, the receptor signaling and internalization were reduced in low $\mathrm{Na}^{+}$concentrations. This is an important observation, suggesting that the functional effects of $\mathrm{Na}^{+}$are not limited to NAM effect on agonist binding. Again, the biochemical and functional effects were selective for $\mathrm{Na}^{+}$compared with $\mathrm{Cs}^{+}$or $\mathrm{NH}_{4}^{+}$.

For the oxytocin receptor, while the endogenous agonist oxytocin was positively modulated by divalent ions like $\mathrm{Mg}^{2+}$, specific NAM effect of $\mathrm{Na}^{+}$on oxytocin binding was detected at physiologic $\mathrm{Na}^{+}$concentration (Schiffmann and Gimpl, 2018). Thus, the increase of $\mathrm{Na}^{+}$concentration from 0 to $300 \mathrm{mM}$ reduced oxytocin affinity $\sim 15$-fold, while no significant effect was observed for $\mathrm{K}^{+}$or other monovalent ions.

For the H1 histamine receptor (Hishinuma et al., 2017), all three agonists studied showed expected NAM effect at $100 \mathrm{mM}$ concentration of $\mathrm{Na}^{+}$. While a maximal NAM effect of $\mathrm{Na}^{+}$was observed for histamine and other two agonists, a set of diverse antagonists showed a whole range of effects from NAM to PAM, with the most pronounced PAM found for the most efficacious second-generation antagonists (antihistamines). While these effects were largely abolished by $\mathrm{D}^{2.50} \mathrm{~N}$ mutation, residual $D^{2.50}$-independent effects were observed for some of the antagonists like fexofenadine, depending on their physicochemical properties. This observation emphasizes that the observed $\mathrm{Na}^{+}$effects are often a combination of specific $\mathrm{D}^{2.50}$ pocket $\mathrm{Na}^{+}$ binding and nonspecific effects due to multiple lowaffinity binding sites and charge screening effect in ligands and receptors.

For the muscarinic receptor subfamily, early studies suggested a classic $\mathrm{Na}^{+}$effect in M2 muscarinic receptors (Rosenberger et al., 1980), recently corroborated by mutation studies (Suga and Ehlert, 2013) and molecular dynamics simulations in M3 muscarinic receptors (Miao et al., 2015). However, a strong nonspecific effect of ionic strength (Birdsall et al., 1979) and ionic 
interactions in the orthosteric pocket may interfere with an accurate assessment of $\mathrm{Na}^{+}$selective binding in this subfamily.

In general, both the magnitude and affinity (e.g., $K_{\mathrm{B}}$ ) of the sodium effect can vary dramatically between receptor and between ligands in the same receptor. As the systematic study for six different receptors shows (Wang et al., 2017), the magnitude of agonist potency change by $\mathrm{Na}^{+}$can exceed 100 -fold for some receptors (e.g., MOR), while in other receptors is barely detectable at less than fivefold (DRD4). This may somewhat correlate with the $K_{\mathrm{B}}$ of the sodium effect, which is shown to be much higher for MOR than for DRD4.

Interestingly, a strong sensitivity to allosteric $\mathrm{Na}^{+}$ was characterized recently for ligands that are allosteric modulators themselves. At the D2 dopamine receptor, the allosteric ligand SB269652 completely loses its modulatory effect in the absence of $\mathrm{Na}^{+}$ion (DraperJoyce et al., 2018). Similarly, allosteric ligands effect in MOR was found to be controlled by $\mathrm{Na}^{+}$presence (Livingston and Traynor, 2014). The effect has been recently observed in other opioid receptors (Livingston et al., 2018), and the authors conclude that disruption of the $\mathrm{Na}^{+}$ion binding site may represent a common mechanism for allosteric modulation of class A GPCRs.

2. Binding of Sodium Not Always Detected by a "Classical" Allosteric Effect. While the negative allosteric modulation of agonist binding has been long considered a hallmark effect of $\mathrm{Na}^{+}$in some GPCRs, this effect may be much less pronounced and can easily go undetected in some cases, even when sodium is known to bind in their conserved pocket. Thus, sodium ion anchored by $\mathrm{D}^{2.50}$ has been resolved in high-resolution $\beta_{1} \mathrm{AR}$ structure, revealing the same $\mathrm{Na}^{+}$/water cluster as in $\mathrm{A}_{2 \mathrm{~A}} \mathrm{R}$ (Miller-Gallacher et al., 2014). But in contrast to $\mathrm{A}_{2 \mathrm{~A}} \mathrm{R}$, any attempts to detect this NAM effect in $\beta_{1} \mathrm{AR}$ have failed, suggesting that the $\beta_{1} \mathrm{AR}$ adrenergic receptor lacks any observable dependence of agonist binding on $\mathrm{Na}^{+}$concentration. In the closely related $\beta_{2} \mathrm{AR}$ (65\% sequence identity), mutations $\mathrm{D}^{2.50} \mathrm{~A}$ or $\mathrm{D}^{2.50} \mathrm{~N}$ disrupting $\mathrm{Na}^{+}$site also failed to detect classic $\mathrm{Na}^{+}$ NAM effect on agonist binding (Strader et al., 1988).

The lack of "classical" NAM sodium effects on GPCRs that actually bind $\mathrm{Na}^{+}$can arise from combination of several factors, such as 1) weak coupling between allosteric and orthosteric pocket conformations, which reduce the magnitude of the allosteric effect and 2) presence of nonspecific binding effects that can at least partially mask/compensate the specific NAM effect. The detection of the "classical" sodium effect can be further complicated in those cases where affinity of $\mathrm{Na}^{+}$binding in the specific pocket is low $\left(K_{\mathrm{B}}>100 \mathrm{mM}\right)$, which makes it harder to differentiate from nonspecific ionic strength effect. Corroborating the first factor above, both $\beta_{1}$ - and $\beta_{2}$-adrenergic receptors are well known to have very weak coupling between extracellular agonist binding and intracellular conformational changes, reflected in their high basal activity $(\sim 20 \%-40 \%)$ and incomplete activation by endogenous ligands (Yao et al., 2009). This weak coupling is reflected also in structural studies, showing the agonist binding per se does not convert $\beta_{1} \mathrm{AR}$ and $\beta_{2} \mathrm{AR}$ to active $\left(\mathrm{R}^{*}\right)$ state (Rosenbaum et al., 2011; Warne et al., 2011), which needs G protein or arrestin binding for stabilization (Rasmussen et al., 2011). Importantly, this carefully documented case of absence of NAM effect of $\mathrm{Na}^{+}$on agonist binding in some GPCRs suggest that this "classical" effect, though most easily measurable in vitro, is not, in fact, essential to the functional role of sodium. The NAM effect on agonist binding is only part of the story and probably not the most biologically important part.

\section{B. Evidence for the Functional Importance of the Sodium Ion Site}

Although the most commonly documented effect of sodium presence in class A GPCRs is NAM, i.e., reduction of agonist binding and reduction in constitutive activity (Quitterer et al., 1996; Seifert and Wenzel-Seifert, 2001; Wang et al., 2017) there is a substantial evidence that physiologic sodium is actually required for efficient stimulation of the receptors in response to agonists. Indeed, as early as 1982, Cooper et al. (1982) noted the amplification effect of $\mathrm{Na}^{+}$on agonist-induced cAMP modulation in rat striatal plasma membrane. More recent studies are further corroborating this hypothesis, including both direct dependence of signaling on $\mathrm{Na}^{+}$concentrations and its displacement by an agonist, as well as indirect effects of mutations in $\mathrm{Na}^{+}$ coordinating residues.

1. Direct Functional Effects of Sodium Ion Presence. Because of the potential interference of changing $\mathrm{Na}^{+}$ concentration with signal transduction downstream from GPCRs, direct measurements of the $\mathrm{Na}^{+}$concentration effect on GPCR signaling are challenging. Nevertheless, several studies demonstrate that such dependencies can be detected in well-controlled assays. Thus in 1982, Cooper et al. (1982) were the first to note the amplification effect of $\mathrm{Na}^{+}$on agonist signaling via opioid receptors in rat striatal plasma membrane. Opioid receptors generally signal via the $G i$ pathway, which inhibits the production of cAMP. The authors found that the presence of $\mathrm{Na}^{+}$at $80 \mathrm{mM}$ concentrations results in a dramatic increase of the cAMP inhibition effect of the morphine agonist, especially at high GTP concentrations.

Sodium effects on spontaneous opioid receptor GTPase activity and relative agonist efficacy were also studied by Costa et al. (1990, 1992), revealing "paradoxical difference in the way sodium ions affect GTPase activity and ligand binding." Most importantly, they showed that buffer exchange from $\mathrm{K}^{+}$to $\mathrm{Na}^{+}$dramatically reduces basal GTPase activity while maintaining the activity of agonist DADLE, thus selectively amplifying the ligand-induced stimulation (Fig. 5A). 

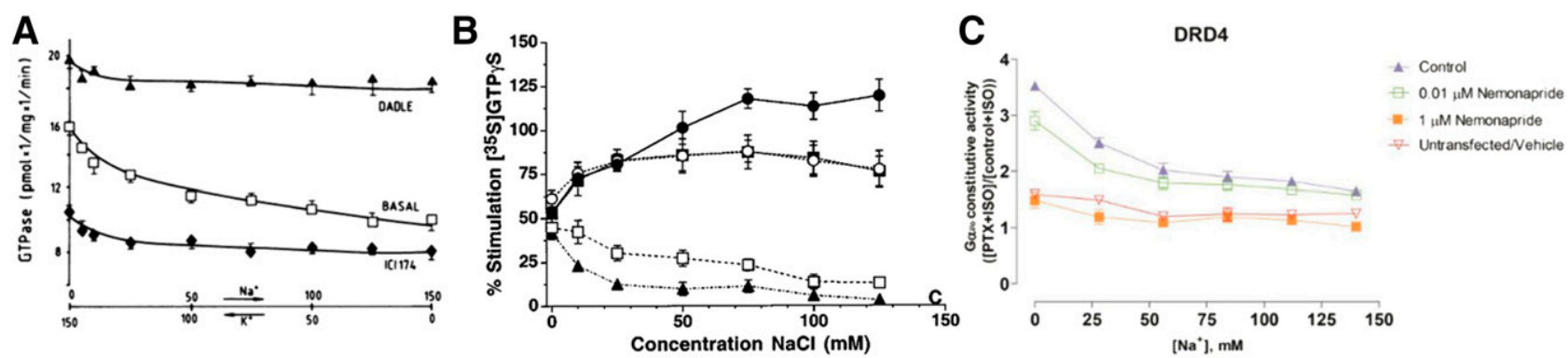

Fig. 5. Direct measurement of $\mathrm{Na}^{+}$effect on GPCR signaling. (A) Exchange of $\mathrm{K}^{+}$to $\mathrm{Na}^{+}$leads to reduced basal activity, but maintains agonistinduced signal (Costa et al., 1990). (B) Addition of $\mathrm{Na}^{+}$dramatically enhances differential between agonists and antagonists of G-protein signaling in MOR (Selley et al., 2000). (C) Addition of $\mathrm{Na}^{+}$reduces basal activity of DRD4 (Wang et al., 2017). This figure reproduced with permission.

Selley et al. (2000) studied the $\mathrm{Na}^{+}$effect on $\left[{ }^{35} \mathrm{~S}\right]-$ GTP $\gamma \mathrm{S}$ binding in $\mathrm{CHO}$ cells stably transfected with MOR (mMOR-CHO cells) and in rat thalamus. In both systems, an increase of sodium concentration to physiologic levels ( $\sim 140 \mathrm{mM})$ had a dual effect of 1 ) reduced basal G-protein signaling and 2) increased receptor stimulation by full agonists, but not partial agonists. In other words, while in the absence of $\mathrm{Na}^{+}$, stimulation by full and partial agonists was almost indistinguishable, increasing $\mathrm{Na}^{+}$concentrations "magnified relative efficacy differences among agonists" (Fig. 5B).

In the recent study on DRD4 (Wang et al., 2017), which combines structural, biochemical, and functional assessment of the receptor, the authors showed that basal (constitutive) activity dependence on $\mathrm{Na}^{+}$can be accurately measured. Thus, the study found that constitutive $\mathrm{G} \alpha_{\mathrm{i} / \mathrm{o}}$ activity at D4 receptor was dramatically (twofold) reduced at physiologic $\mathrm{Na}^{+}$concentrations. The potentiation of DRD4 constitutive activity in low $\mathrm{Na}^{+}$concentration can be abolished by selective DRD4 antagonist nemonapride, showing that the effect is entirely D4 receptor-mediated (Fig. 5C).

The aforementioned study of V1b vasopressin receptors (Koshimizu et al., 2016) also shows that agonist binding at high $\mathrm{Na}^{+}$concentrations was reduced. However, IP3 production assays showed that $\mathrm{Na}^{+}$in the external buffer was required for signaling. Thus, in the NaCl-containing buffer, the agonist increased the IP3 level from basal $6.6 \pm 1.2$ to $13.2 \pm 0.7 \mathrm{nM}$ in the stimulated receptor. In contrast, in the buffer without $\mathrm{NaCl}$, the agonist-stimulated IP3 levels were below the detection level ( $<1 \mathrm{nM})$. These biochemical and functional effects were selective for $\mathrm{Na}^{+}$compared with $\mathrm{Cs}^{+}$or $\mathrm{NH}_{4}^{+}$.

In general, all these results suggest that presence of sodium at physiologic concentrations both reduces the basal activity of receptors and enhances the stimulated response to agonist, thus selectively enhancing the overall efficacy of full agonists. The effects were selective to $\mathrm{Na}^{+}$, as shown in $\mathrm{K}^{+}$replacement experiments. Importantly, when the studies were able to accurately titrate sodium allosteric effects on signaling, whether basal or ligand induced (Costa et al., 1990; Selley et al., 2000; Wang et al., 2017), the $\mathrm{Na}^{+}$response curves show
$K_{\mathrm{B}}$ or $\mathrm{EC}_{50}$ values in the range of $\sim 10-200 \mathrm{mM}$, approximately corresponding to the affinity of $\mathrm{Na}^{+}$in the conserved sodium pocket of these receptors.

2. Mutations in Sodium Ion Pocket Reduce or Abolish Receptor Stimulation by Agonists. A substantial body of evidence for the functional role of $\mathrm{Na}^{+}$comes from indirect studies showing the dramatic impact of mutations in the sodium coordinating residue's classic allosteric binding effect and on signaling function of at least 20 class A GPCRs, as presented in Table 1 of our previous review (Katritch et al., 2014). Several recent studies corroborate these observations, suggesting that removal of $\mathrm{Na}^{+}$site via mutations often has similar consequences as removal of $\mathrm{Na}^{+}$itself from solution. Thus Massink et al. (2015) show that while in $\mathrm{A}_{2 \mathrm{~A}}$ adenosine receptor mutations in sodium-coordinating residues $\mathrm{S}^{3.39}$ and $\mathrm{N}^{7.45}$ reduce or abolish classic dependence of agonist binding on $\mathrm{Na}^{+}$, they also increased basal activity and reduced the maximal activity (Emax) of the agonist-induced signal. These mutations result in about a fivefold reduction of total cAMP response to ligand compared with the wild-type signal. Importantly, the mutations did not reduce but even slightly improved $\mathrm{EC}_{50}$ values of agonists in these assays, which is similar to improved agonist affinities in lieu of $\mathrm{Na}^{+}$. In the case of the $\mathrm{D}^{2.50} \mathrm{~N}(\mathrm{~A})$ mutations (Massink et al., 2015; White et al., 2018) in adenosine $\mathrm{A}_{2 \mathrm{~A}} \mathrm{AR}$, however, any cAMP activity (basal or induced) of the mutants was disrupted, suggesting that in addition to the $\mathrm{Na}^{+}$anchoring role, $\mathrm{D}^{2.50}$ has other roles in the receptor activation, which may also be related to dynamic change in its protonation state (Vickery et al., 2018). A similar effect was recently observed for GPR3, where $\mathrm{D}^{2.50} \mathrm{~A}$ mutation in a recently characterized sodium site completely abolished signaling (Capaldi et al., 2018).

Interestingly, constitutively active mutants have been also observed in a number of class A GPCRs in position 3.43 at the bottom of the sodium pocket, where conserved hydrophobic residues Leu ( $\sim 74 \%$ receptors) or Met $(\sim 20 \%)$ comprise a hydrophobic layer, keeping the gate closed to the waters and $\mathrm{Na}^{+}$ion escaping toward the intracellular side (Yuan et al., 2014). One of the studies showed that replacing Leu or Met with any small or polar group in 3.43 position (Arg, Lys, or Ala) 
all resulted in constitutive activation in thyrotropin receptor (TSHR), but also in $\beta_{2} \mathrm{AR}$, luteinizing hormone (LHR), and follitropin (FSHR) receptors (Tao et al., 2000). Apparently, mutations breaking the hydrophobic layer facilitate $\mathrm{Na}^{+} /$water cluster disruption and egress into the cytoplasm, activating receptors even without agonist.

3. A Gain of Function by Introducing Acidic Residues in Sodium Ion Pocket. The importance of allosteric $\mathrm{Na}^{+}$binding itself is further corroborated by gain-offunction effects, when acidic residues in the pocket other than $\mathrm{D}^{2.50}$ were found to restore, at least partially, signaling function of the receptor lacking $\mathrm{D}^{2.50}$. Such gain of function studies performed for the $5-\mathrm{HT}_{2 \mathrm{~A}}$ serotonin receptor and $\mu$-opioid receptor show that whereas the $D^{2.50} \mathrm{~N}$ mutant abrogated receptor coupling to G-protein, double mutant $\mathrm{D}^{2.50} \mathrm{~N} / \mathrm{N}^{7.49} \mathrm{D}$ with another Asp in position 7.49 restored $\mathrm{Na}^{+}$binding and regained most of the functional activity (Sealfon et al., 1995; Xu et al., 1999). Similarly, some GPCRs, for example the sodium-dependent GnRHR, have these residues naturally reversed as $\mathrm{N}^{2.50}$ and $\mathrm{D}^{7.49}$ in the wild-type protein (Flanagan et al., 1999). Another $\mathrm{Na}^{+}$coordinating position of the pocket, 3.39, also bears Glu in a few olfactory receptors that lack $\mathrm{D}^{2.50}$, which likely helps them to retain their $\mathrm{Na}^{+}$binding properties and signaling.

4. Disease-Associated Mutations in the Sodium Pocket. Because GPCRs play a critical role in many biologic and pathologic pathways, missense mutations modifying their signaling response underlie many monogenic disorders in retinal, endocrine, metabolic, developmental, and other systems (Spiegel and Weinstein, 2004; Insel et al., 2007; Vassart and Costagliola, 2011). Some of the critical mutations occur in the sodium pocket residues, impacting their functional profile. Thus, a disease-relevant SNP in CLTR2 cysteinyl leukotriene receptor residue L129 $9^{3.43}$ has been associated with uveal melanoma and blue nevi (Moore et al., 2016; Moller et al., 2017). Like other mutations in this position described above, the L129 ${ }^{3.43} \mathrm{~N}$ mutant of CLTR2 receptor constitutively activates endogenous $\mathrm{G} \alpha_{\mathrm{q}}$ and is unresponsive to stimulation by leukotriene (Moore et al., 2016).

As predicted recently by Hauser et al. (2018), many more GPCR point mutations documented in the Exome Aggregation Consortium database may be pathologically and therapeutically relevant and many of them are located in the sodium pocket. More than 220 potential disease-associated mutations have been suggested in the sodium pocket of more than 80 different clinical targets of class A GPCRs (Hauser et al., 2018). Of these, mutations at $\mathrm{D}^{2.50}$ position were predicted to be deleterious in 24 different class A GPCRs, $\mathrm{S}^{3.39}$ in $14, \mathrm{~N}^{7.45}$ in $13, \mathrm{~S}^{7.46}$ in 15 , and $\mathrm{Y}^{7.53}$ in 15 GPCRs. Most of these SNPs are exceedingly rare $\left(\right.$ rate $<10^{-4}$ ) or unique, making their disease association hard to detect and statistically validate. Thus, understanding of their functional role can facilitate full biochemical and in vivo characterization of the mutants, leading to new diagnostics tools for range diseases. Importantly, as the effect of mutations can vary from elevated basal activity to reduced or completely abolished signaling, the same receptor may have several different disease associations.

\section{Mechanism of Sodium Ion Functional Involvement}

1. Sodium as an Allosteric Cofactor of Class A G-Protein-Coupled Receptor Signaling. The above evidence suggests that along with selective NAM effects on agonist binding, physiologic concentrations of $\mathrm{Na}^{+}$ can reduce the basal activity of receptors and, overall, enhance the magnitude of their stimulation by full agonists. These opposing effects of $\mathrm{Na}^{+}$on agonist binding and signaling response at GPCRs have been characterized with $\mathrm{EC}_{50}$ or $K_{\mathrm{B}}$ values in the same 20-100 $\mathrm{mM}$ concentration range, and the effects can be abolished by $\mathrm{D}^{2.50} \mathrm{~N}$ or other mutations in the sodium pocket, suggesting a common functional mechanism that involves $\mathrm{Na}^{+}$binding in the conserved pocket. In 2014, we (Katritch et al., 2014) proposed a dynamic mechanism of $\mathrm{Na}^{+}$as an allosteric cofactor in class A GPCR ligand induced signal transduction. It involves $\mathrm{Na}^{+}$entrance into the conserved pocket from the extracellular side and along the hydrated channel, which is opened in most class A GPCRs. The extracellular entrance of $\mathrm{Na}^{+}$, also observed in all MD simulations (see section V.B below) is also corroborated by the fact that the intracellular side of the pocket of class A GPCRs in an inactive state is sealed by the "hydrophobic layer" right beneath the sodium. Moreover, the intracellular entrance of $\mathrm{Na}^{+}$is hindered by a major electrostatic barrier due to excess of positive charges (as high as 10-15) found at the cytoplasmic side of receptors. It is well established that the presence of the sodium/water cluster in the conserved pocket stabilizes the receptor in the inactive state, reducing its basal activity and reducing the availability of high-affinity binding sites for agonists (Chung et al., 2011). Unlike agonists, binding of most antagonists is compatible with $\mathrm{Na}^{+}$binding and therefore a synergistic stabilization of inactive state by $\mathrm{Na}^{+}$can enhance the affinity of antagonists and inverse agonists.

During activation-related rearrangements in the 7TM bundle and the sodium pocket, $\mathrm{Na}^{+}$becomes dislodged from its position in the pocket and exits toward cell cytoplasm via the opening formed in the hydrophobic layer upon activation (Yuan et al., 2013). Importantly, the extracellular entrance and intracellular egress of $\mathrm{Na}^{+}$comprises a transfer of $\mathrm{Na}^{+}$ion across cell membranes. This transfer goes along with the gradient of $\mathrm{Na}^{+}$concentration, which is $\sim 10$ - to 20 -fold higher at the extracellular side, as well as 
with electrostatic potential on the plasma membrane, and the reverse transfer against the electrochemical gradient is very unlikely. It was estimated that the transmembrane transfer of $\mathrm{Na}^{+}$along with gradient would result in $\sim 3 \mathrm{kcal}$ gain in energy, and this transfer can be coupled with signal amplification in class A GPCRs observed in presence of $\mathrm{Na}^{+}$.

One of the more recent studies also pointed to possible protonation of $\mathrm{D}^{2.50}$ upon activation, where increased mobility of $\mathrm{Na}^{+}$in the pocket results in higher $\mathrm{p} K_{\mathrm{a}}$ of this acidic side chain (Vickery et al., 2018). Such protonation would result in the total disappearance of the barrier for sodium intracellular egress and thus facilitate activation (Fig. 6).

\section{Other Potential Functional Effects of the Conserved Sodium Ion Binding}

1. Voltage Sensing. Selective transfer of $\mathrm{Na}^{+}$positive charge through the GPCR transmembrane bundle and coupling of this transfer with receptor activation is likely to make GPCRs sensitive to both sodium concentration gradient and the electrostatic potential on the membrane (Ben-Chaim et al., 2006). Several recent studies, indeed, showed that membrane voltage increased the sensitivity of the $\alpha_{2 \mathrm{~A}}$ adrenoreceptor to norepinephrine (Rinne et al., 2013). Activation of another adrenergic receptor, the $\beta_{1} \mathrm{AR}$, by catecholamine agonists was also shown to be positively modulated by membrane voltage, while depolarization of membrane dramatically reduced signaling (Birk et al., 2015). Similarly, voltage sensitivity of muscarinic acetylcholine receptors to their full agonists was shown for M2, M3, and M5 subtypes (Navarro-Polanco et al., 2011; Rinne et al., 2015). Several studies, including MD-simulations in M2 and the $\delta$-opioid receptor (Vickery et al., 2018), suggested that $\mathrm{Na}^{+}$binding in the sodium pocket may explain such voltage sensitivity. Limited experimental data from live cell assays, however, have not been conclusive so far. While $D^{2.50}$ mutations to Ala (Navarro-Polanco et al., 2011) or Asn (Barchad-Avitzur et al., 2016) eliminated gating currents in M2R, voltage sensitivities for agonist binding and conformational changes of the receptor were still present in the mutant (Barchad-Avitzur et al., 2016). This suggests the presence of multiple voltage sensors in muscarinic receptors (Hoppe et al., 2018) and calls for similar assessments of voltage sensitivity in other class A GPCRs, where the effect may be more well defined.

2. $p H$ Dependence. Protonation of $\mathrm{D}^{2.50}$ has been proposed as a facilitator of $\mathrm{Na}^{+}$egress from class A GPCRs, thus shifting the conformational equilibrium toward their active state and facilitating signaling (Vickery et al., 2018; Hu et al., 2019). This mechanism is consistent with in vitro observations that lower $\mathrm{pH}$ increases both basal and ligand-induced activation, for example in the $\beta_{2} \mathrm{AR}$ (Ghanouni et al., 2000). This $\mathrm{pH}$ dependence may have important physiologic consequences because, in addition to classic cell membrane signaling, GPCR have been shown to be signaling for an extended period of time from endosomes, where $\mathrm{pH}$ is dramatically shifted toward an acidic environment (Calebiro et al., 2010; Irannejad et al., 2013; Vilardaga et al., 2014; Godbole et al., 2017; Eichel and von Zastrow, 2018). The conserved $\mathrm{Na}^{+}$site protonation would establish a common mechanism for $\mathrm{pH}$ dependence for the majority of class A GPCRs; however, more data and further details of the proton transfer need first to be established.

\section{Ion Binding Sites as Ligand Targets-New Approaches to Design Functional Properties}

Beyond their physiologic importance, can the ion binding sites in GPCRs be directly exploited for the

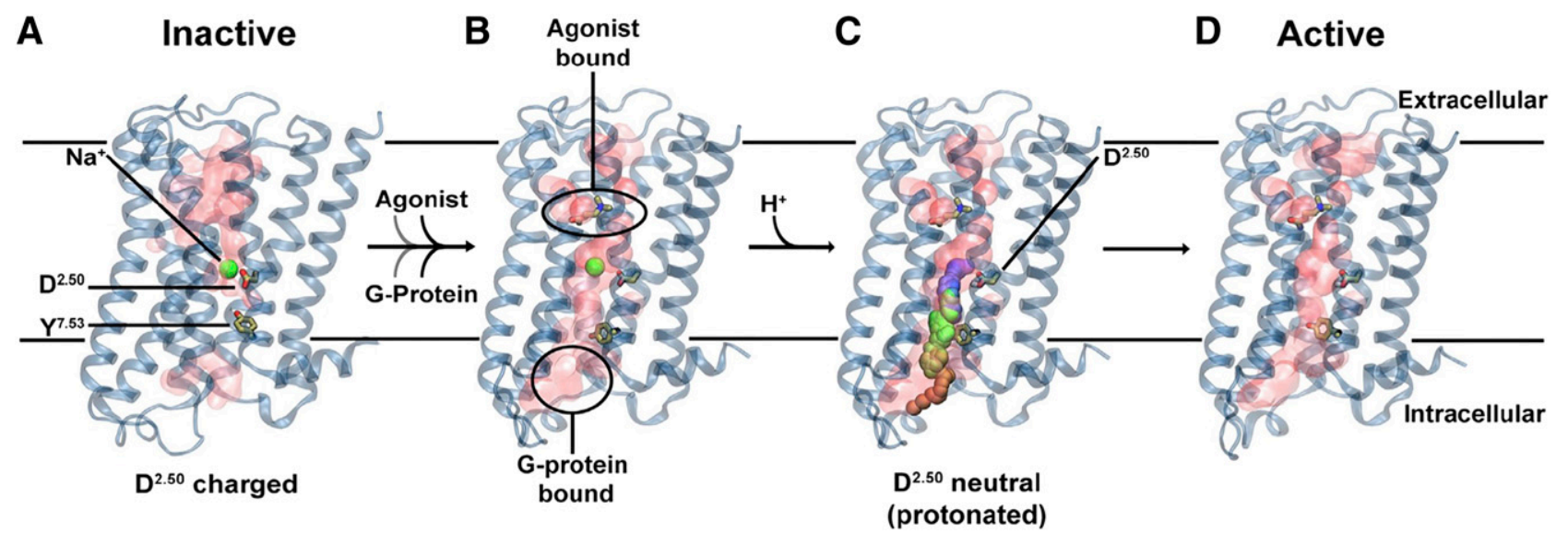

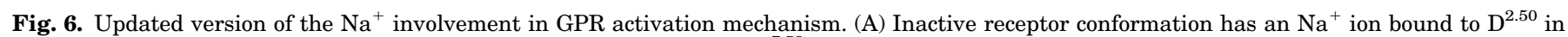

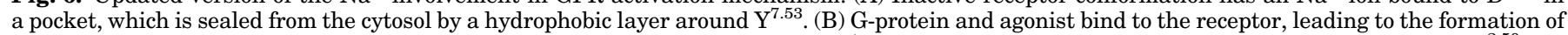

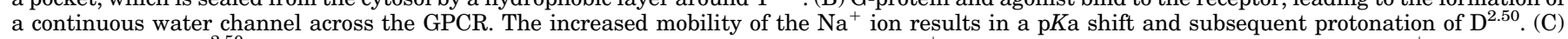

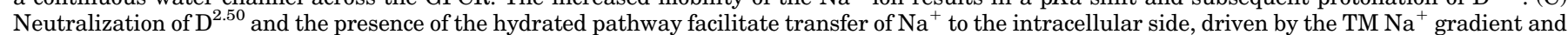

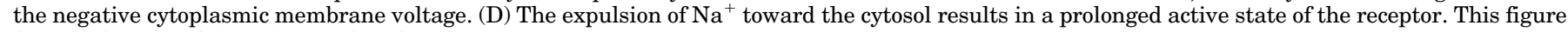
from Vickery et al. (2018) reproduced with permission. 
discovery of new ligands with potentially therapeutically relevant properties? Indeed, structure-based analysis of known GPCRs suggests that ion binding sites can be critical for designing both subtype and functionally selective ligands (Fig. 7).

\section{A. Targeting Nonconserved Ion Binding Sites for Subtype Selectivity}

Targeting selective ionic interactions can often serve as a beneficial strategy for creating subtype selectivity within closely related subfamily members, with some of such cases being characterized pharmacologically and structurally. One of the examples is the development of highly selective drugs for the $\mathrm{H} 1$ histamine receptor (H1R) (Fig. 7D). While the first generation of antihistamines, including doxepin, were not subtype selective, the crystal structure of the H1R-doxepin complex revealed a phosphate ion tightly bound in the extracellular loop (ECL) region and coordinated by nonconserved basic side chains K179 ${ }^{\mathrm{ELC} 2}$ and K191 ${ }^{5.39}$ (Shimamura et al., 2011). Docking of the second generation antihistamines like acrivastine, levocetirizine, and fexofenadine showed that H1R selectivity and thus improved safety and pharmacological profile of these drugs can be explained by their acidic carboxy groups mimicking the interactions of the $\mathrm{PO}_{4}^{3-}$ ions.

Interactions with ion binding sites must be taken into consideration in other cases of design of GPCR ligands. The GPR39A, recently identified as $\mathrm{Zn}^{2+}$ modulated receptor, presents a good example of ligand identification for an ion-binding receptor. Ligands were discovered by medium-throughput screening assays, which detected selective modulation of $\mathrm{Zn}^{2+}$ activity on this GPCR39A (Sato et al., 2016). Another interesting example is protonsensing receptor GPR68, where the proton site has been detected via a combination of molecular modeling and

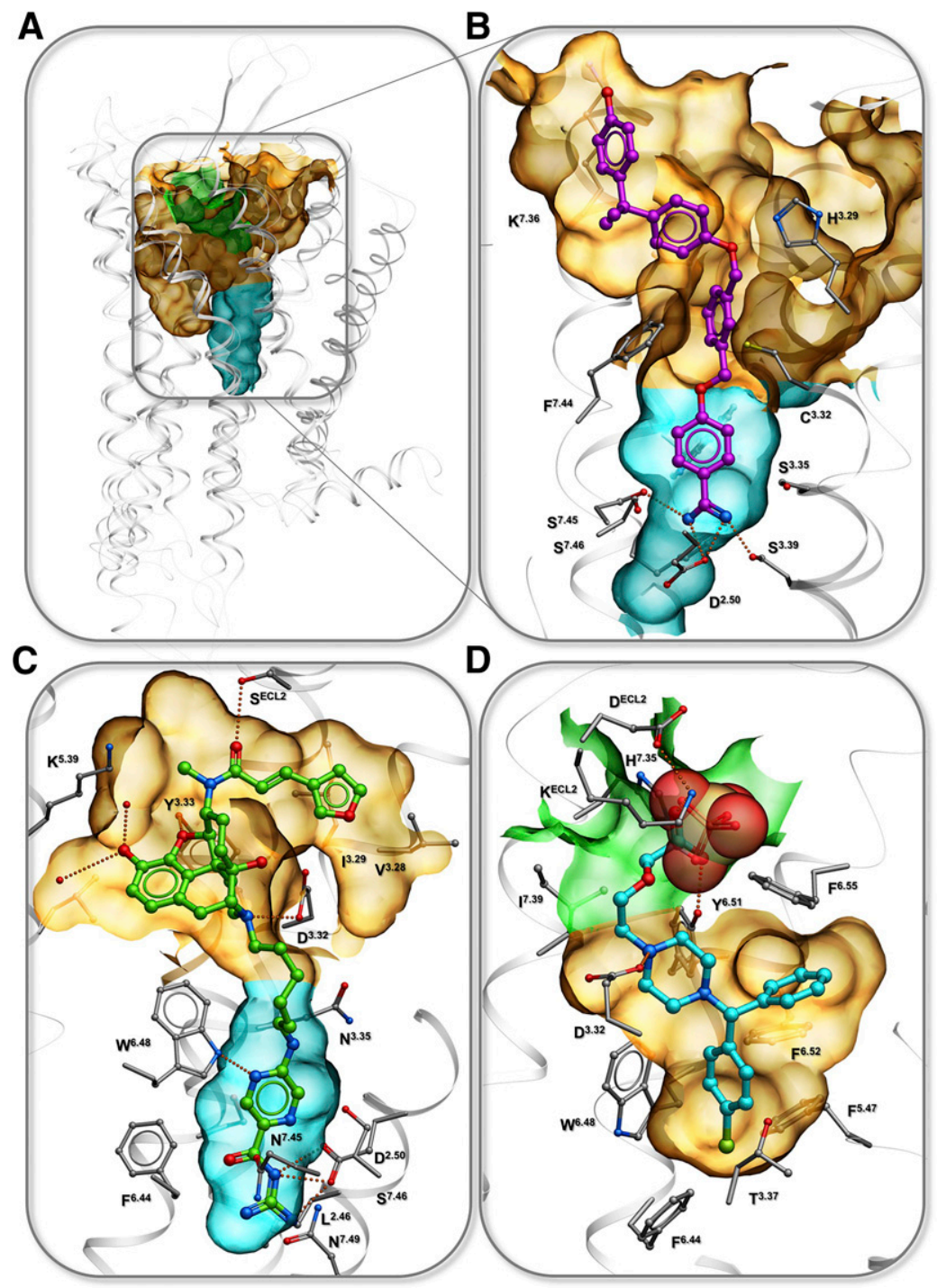

Fig. 7. GPCR pockets for binding bitopic ligands that target specific ion binding sites. (A) Overview of the pocket positions in 7TM domain. (B) structure of BTL1 receptor with bitopic ligand, PDB: 5X33 (Hori et al., 2018). (C) Model of bitopic ligands designed for binding to KOR Na ${ }^{+}$allosteric site (Zaidi et al., 2019). (D) Structure of complex with orthosteric ligand and PO4 ${ }^{3-}$ ion, PDB: 3RZE (Shimamura et al., 2011). In all panels, semitransparent surface shows orthosteric pocket (orange), allosteric conserved sodium pocket (cyan), and allosteric site in EC loops (green). 
mutagenesis (Huang et al., 2015b). After initial detection of lorazepam as a selective positive allosteric modulator of the proton activation in GPR68, homology modeling and ligand guided optimization approaches were used to develop a model for virtual screening of $\sim 3 \mathrm{M}$ available compounds. The screening yielded several new selective PAMs for GPR68, some of them showing in vivo activity (Huang et al., 2015b). Rapidly improving availability of receptor structures and more relevant templates for structural homology modeling makes such approaches more and more practical in application to other ion-binding GPCRs.

\section{B. Allosteric Ligand Binding in the Conserved Sodium Ion Site}

The importance of the conserved $\mathrm{Na}^{+}$site for the function of class A GPCRs suggests that targeting this site with allosteric or bitopic ligands may be a viable general strategy for modulation of these receptor signaling. The volume of the pocket is usually about $150-250$ $\AA^{3}$, thus permitting binding of small fragment-like molecules. Indeed, the $\mathrm{Na}^{+}$pocket has been characterized as a binding site of an antidiuretic drug, sodium channel blocker amiloride, and its derivatives (Liu et al., 2012b). Amilorides are known as negative allosteric modulators (NAMs) of many class A GPCRs, including adenosine (Howard et al., 1987; Leppik et al., 2000; Gao et al., 2003a,b, 2011; Gutiérrez-de-Terán et al., 2013), dopamine (Neve, 1991; Hoare et al., 2000), muscarinic (Dehaye and Verhasselt, 1995), 5-HT (Pauwels, 1997), GnRHR (Heitman et al., 2008), and potentially many more receptors, as summarized in Katritch et al. (2014). Various affinity estimates for amiloride derivatives show $K_{\mathrm{B}}$ raging from $\sim 1$ to $50 \mu \mathrm{M}$ in their negative allosteric modulation of orthosteric ligand binding. Docking of amiloride and a bulkier derivative HMA (5-( $N, N$-hexamethylene)amiloride) (Gutiérrez-de-Terán et al., 2013) shows that the positively charged guanidine moiety of the ligand forms a salt bridge to the $\mathrm{D}^{2.50}$ carboxyl, while the bulkier N5 substituents point toward the orthosteric site. The induced docking and conformational modeling also suggested that the fitting of amilorides, especially HMA into the pocket, requires substantial expansion of the pocket, which manifested in adjustments in the $\mathrm{N}^{7.45}, \mathrm{~N}^{7.49}$, and especially $\mathrm{W}^{6.48}$ side chains. Accordingly, mutations of these residues to alanine in this study only improved affinity of amiloride and HMA severalfold, suggesting that amiloride might not be the optimal chemotype for targeting the pocket. On the chemistry side, a number of additional amiloride derivatives with longer $5 \mathrm{~N}$ substitutes were characterized in a recent study (Massink et al., 2016), showing that extension of the allosteric ligand into the orthosteric pocket is possible without major reduction of the binding affinity.

Another small molecule characterized recently as an allosteric $\mathrm{Na}^{+}$pocket binder in the BLT1 receptor is benzamidine (Hori et al., 2018), though its affinity $\left(K_{\mathrm{B}}\right)$ was estimated much lower than amiloride at $\sim 500 \mu \mathrm{M}$, making it only $\sim 10$ times more potent than $\mathrm{Na}^{+}$ion itself (based on Fig. 4A in Hori et al., 2018). The study revealed binding of benzamidine and its NAM effect on G-protein activity in two very different receptors, the BLT1 receptor and $\beta 1 \mathrm{AR}$, suggesting that it likely binds at the sodium ion binding site in other class A GPCRs as well.

Intriguingly, because $\mathrm{Li}^{+}$can compete with $\mathrm{Na}^{+}$in the conserved pocket (Pert et al., 1973), some studies hypothesized that effects of $\mathrm{Li}^{+}$on functional properties of GPCRs can be implicated in physiologic and psychoactive effects of the $\mathrm{Li}^{+}$(Dudev et al., 2018). The $\mathrm{Li}^{+}$ effect as a competitor to $\mathrm{Na}^{+}$binding is especially intriguing because lithium is widely used in treatment of bipolar disorders; however, more evidence is needed to establish the GPCR mode of action of $\mathrm{Li}^{+}$, as this ion can also impart a central nervous system effect via ion channel modulation.

\section{Targeting Sodium Ion with Bitopic Ligands}

1. Concept of Bitopic Ligands. The highly conserved nature and small size of the sodium pocket itself limit its selectivity, and therefore, the practical utility of small ligands like amilorides and benzamidines as allosteric modulators. On the other hand, a combination of high affinity selective orthosteric moieties with the unique functional properties of the $\mathrm{Na}^{+}$site allosteric binders could make bitopic ligands an attractive target for ligand design. One recently characterized example of such a bitopic ligand is benzamidine-containing ligand BIIL260 found in the BTL1 receptor structure (Hori et al., 2018). By reaching into the $\mathrm{Na}^{+}$site and forming a salt bridge with $\mathrm{D}^{2.50}$ carboxyl, as well as hydrogen bonds to $\mathrm{S}^{3.39}$ and $\mathrm{S}^{7.45}$, the positively charged benzamidine moiety is expected to block activation related changes. In agreement with this prediction, BIIL260 was characterized as an inverse agonist, completely blocking the basal activity of the receptor. There are several other benzamidine-containing compounds for BLT1 predicted to bind in a similar manner (Hori et al., 2018).

2. Structure-Based Design of Bitopic Ligands for the Sodium Ion Site. Structure-based rational design of bitopic ligands targeting $\mathrm{Na}^{+}$site of class A GPCRs was proposed as a potentially broadly applicable mechanism for developing selective ligands with beneficial functional properties, including, e.g., inverse agonism (Katritch et al., 2014). Such design in application to opioid receptors been performed recently (S. Zaidi, T. Che, B. Roth, and V. Katritch, manuscript in preparation). The structure-based design of these ligands (see Fig. 7) is based on the orthosteric agonist nalfurafine, extending its morphinan scaffold at N5 toward the sodium pocket. Both bitopic ligands synthesized and tested, BRI-731 and BRI-751, show high affinities at 
the three opioid receptors and retain full $G_{i}$ agonism of nalfurafine. At the same time, the ligands, and especially guanidine-containing BRI-751, effectively block arrestin recruitment, which makes them highly $G_{i}$-biased agonists. The ability of bitopic ligands to block arrestin signaling can be explained by the conformational mechanism, where the allosteric moiety (e.g., amiloride) blocks inward movements of TM7 in the $\mathrm{Na}^{+}$pocket, while still allowing outward movement of TM6. Indeed, several previous studies, e.g., by NMR (Liu et al., 2012a) and fluorescent spectroscopy (Rahmeh et al., 2012), established a direct connection between dynamical changes in TM6 and G-protein biased signaling, while TM7 was associated with arrestin-biased signaling. Like the amiloride derivatives described above, the improved affinities of BRI-751 in the Ala mutants of the pocket side chains suggest that the $\mathrm{Na}^{+}$site is slightly too small for these moieties and that further optimization could improve the ligand affinities to wild-type receptors.

\section{Biophysical and Computational Approaches for Studying Allosteric Ions}

As ions impact many aspects of GPCR function, often in subtle dynamic ways, a comprehensive multidisciplinary approach is often needed to fully understand the observed effects. In addition to the key evidence from biochemical and pharmacological studies of allosteric ion effects and structural studies revealing ion binding sites, biophysical and computational approaches make an increasingly important contribution to our understanding of ion dynamics and functional role.

\section{A. Nuclear Magnetic Resonance Spectroscopy}

1. Study of G-Protein-Coupled Receptor Dynamics with and without Sodium Ion Site. Nuclear magnetic resonance (NMR) approaches have been widely applied to study conformational dynamics of GPCRs, complementing static the picture produced by crystallography, and the recent examples show that it can greatly contribute to the understanding of the role of ions in GPCR function. Thus, in a recent study (Eddy et al., 2018b) characterized the dynamic behavior of the $\mathrm{A}_{2 \mathrm{~A}}$ adenosine receptor $\left(\mathrm{A}_{2 \mathrm{~A}} \mathrm{AR}\right)$ by assessing NMR spectra of Trp and Gly residues in complexes with specific agonists and antagonists. The study showed that the $\mathrm{D}^{2.50} \mathrm{~N}$ mutation disrupting the $\mathrm{Na}^{+}$site can drastically reduce signaling-related dynamics in the intracellular half of the receptor, while not affecting conformational dynamics in the extracellular ligand binding half. This is in perfect agreement with the "uncoupling" role of $\mathrm{D}^{2.50} \mathrm{~N}$ mutation that abolishes G-protein activation in $\mathrm{A}_{2 \mathrm{~A}} \mathrm{AR}$ (Eddy et al., 2018a) and validates the dynamic nature of the $\mathrm{Na}^{+}$allosteric effect.

2. Direct Nuclear Magnetic Resonance Assessment of Allosteric Sodium Ion Binding Kinetics. Recent NMR studies show that the effect of sodium and divalent cations on GPCR signaling dynamics can be assessed directly by NMR (Eddy et al., 2018b; Ye et al., 2018). These studies, also performed with $\mathrm{A}_{2 \mathrm{~A}} \mathrm{AR}$, demonstrated that increasing concentrations of $\mathrm{Na}^{+}$selectively shift the equilibrium toward an inactive ensemble, while the addition of $\mathrm{K}^{+}$does not have such effect. Moreover, the Ye et al. (2018) study used ${ }^{23} \mathrm{Na}$ NMR binding isotherm to achieve the first direct measurement of the dissociation constant of $\mathrm{Na}^{+}$in apo $\mathrm{A}_{2 \mathrm{~A}} \mathrm{R}$ as $K_{\mathrm{d}}=$ $61 \pm 27 \mathrm{mM}$, which is in good agreement with previous indirect estimations of $\mathrm{Na}^{+}$allosteric effects $K_{\mathrm{B}}=$ $32 \mathrm{mM}$ (Massink et al., 2015). Furthermore, relaxation dispersion (CPMG) experiments with ${ }^{23} \mathrm{Na}$ provided a first measure of the bound state lifetime. In the apo state, the specific $\mathrm{Na}^{+}$bound lifetime was estimated at $480 \mu \mathrm{s}$, in agreement with lack of $\mathrm{Na}^{+}$ dissociation in the shorter time scales of $<10 \mu \mathrm{s}$ in molecular dynamic simulations of the inactive state. As expected, binding of the antagonist ZM241385 increased the bound fraction of $\mathrm{Na}^{+}$by $20 \%$ and the average bound state lifetime to $630 \mu \mathrm{s}$. Another important observation in this study involves amiloride analog HMA, which was shown by NMR to compete with sodium weakening its effect on titration isotherm.

3. Binding and Effect of Divalent Ions in $A_{2 A}$ Adrenergic Receptor is Potentially Nonspecific. In stark contrast with $\mathrm{Na}^{+}$effects, the same NMR study (Ye et al., 2018) shows that the allosteric effects of divalent cations at $\mathrm{A}_{2 \mathrm{~A}} \mathrm{AR}$ appear to be nonselective, at least between $\mathrm{Ca}^{2+}$ and $\mathrm{Mg}^{2+}$, and require non-physiologically high concentrations (100-500 mM) of these ions. The divalent ions shifted the equilibrium toward active states of the receptor, and this shift was synergistic with agonist binding, which is similar to observations for divalent ions found in opioid receptors earlier (Pert et al., 1973). The MD simulations in this study suggested that at high cation concentrations they can bind in the extracellular loops of the receptor, bridging the key acidic residues and contracting the pocket, thus facilitating agonist binding and receptor activation.

\section{B. Molecular Dynamic Simulations}

Owing to its ability to look into atomistic details and generate hypotheses for experimental validation, molecular dynamics (MD) simulations have become an important tool for deciphering roles of ions in GPCR function. On the other hand, adequate modeling of ions, especially $\mathrm{Na}^{+}$, is becoming a requirement for adequate MD studies of functional effects in most GPCRs, in the same way as ions are absolutely required in the modeling of ion channels.

1. Sodium Access and Universality of Sodium Ion Binding in Class A G-Protein-Coupled Receptors. Starting from the pioneering work on the $\mathrm{Na}^{+}$access into the allosteric pocket in dopamine receptors (Selent et al., 2010), a number of studies characterized $\mathrm{Na}^{+}$ access kinetics in opioid (Shang et al., 2014) and muscarinic (Miao et al., 2015; Vickery et al., 2016) 
receptors. Moreover, conventional and accelerated MD simulations were recently performed systematically for 18 different GPCRs with known 3-D structures by Selvam et al. (2018). The studies predict similar sodium entry pathways from the extracellular side into the 2.50 pocket for 15 of these diverse class A receptors. Interestingly, the predicted average mean first passage time for $\mathrm{Na}^{+}$ranged from about 0.1 to $0.3 \mu \mathrm{s}$ in opioid and orexin- 2 receptors, which have relatively open access to the sodium pocket, to $\sim 30 \mu$ s in sphingosine1-phosphate receptors, which has the extracellular entrance into the receptor obscured by the extracellular (EC) loops. In two of the receptors assessed, the PAR1 protease activated receptor and the P2Y12 purinergic receptor, occlusion of the EC access blocked the extracellular entrance of $\mathrm{Na}^{+}$during the modeling time, even though PAR1 and PAR2 protease activated receptor crystal structures have $\mathrm{Na}^{+}$resolved in the conserved pocket. These observations suggest that either $\mathrm{Na}^{+}$ enters PAR1/PAR2 from the intracellular side against the gradients and electrostatic potential (which is unlikely), or thermal and ligand-induced conformational changes in the EC loops can dynamically open the access for $\mathrm{Na}^{+}$from the outside of the cell. This study (Selvam et al., 2018) also predicted very long average unbinding times for the $\mathrm{D}^{2.50}$ anchored $\mathrm{Na}^{+}$, ranging from $13 \mu \mathrm{s}$ in the adenosine receptor to $\sim 120 \mu \mathrm{s}$ in the orexin-2 receptor. This estimate is approaching the same order of magnitude $(480 \mu \mathrm{s})$ as measured by the NMR study (Ye et al., 2018). While the MD was also used to simulate $\mathrm{Na}^{+}$binding to a nonconserved site in the class $\mathrm{B}$ glucagon receptor, the predicted class $\mathrm{B}$ binding was very weak and unstable, with unbinding times much faster $(2 \mu \mathrm{s})$ than binding times $(27 \mu \mathrm{s})$, which further contrasts with strong and highly selective $\mathrm{Na}^{+}$binding in class A receptors.

2. Molecular Dynamic Simulations Corroborate New Functional Hypotheses. Molecular dynamic simulations also suggest some intriguing details of $\mathrm{Na}^{+}$-dependent functions. Thus, Vickery et al. (2016) used the CompEL approach to simulate the $\mathrm{Na}^{+}$gradient and the voltage across the membrane in MD simulations with $\delta$-OR and M2R. The study suggested that the sodium movement along the transmembrane domain in the water-filled pocket can create a gating charge of $0.5 \mathrm{e}$ when the ion travels between the extracellular entry and the allosteric binding site, which would make the receptor highly sensitive to membrane polarization and depolarizations as occurs in neuron signaling. Moreover, another study (Vickery et al., 2018) used comprehensive MD-based $\mathrm{pKa}$ predictions to show that $\mathrm{D}^{2.50}$ is likely to become protonated when active-like conformation of the receptors and increased mobility of $\mathrm{Na}^{+}$can lead to $\mathrm{D}^{2.50}$ protonation, followed by fast and barrier-free egress of $\mathrm{Na}^{+}$into the cytoplasm.

Another recent MD study on $\mu$-opioid receptor (MOR) used a $>11 \mu$ s Markov State Model ensemble MD simulation to identify the continuous egression path for $\mathrm{Na}^{+}$in the MOR active state (Hu et al., 2019). This work draws similar conclusions, showing that protonation of $\mathrm{D}^{2.50}$ can greatly facilitate $\mathrm{Na}^{+}$egress from the cytosol in an active MOR. The combination of MD with machine learning also provides insight into conformational changes accompanying $\mathrm{Na}^{+}$movements, predicts energetics, and time scales of $\mathrm{Na}^{+}$ translocation in inactive and active MOR, as well as qualitatively predicts impact of $\mathrm{Na}^{+}$binding on agonist affinity. Interestingly, the predicted timescales for sodium intracellular relocation on the order of 1 second are comparable to the experimentally derived lifetimes of GPCR/G protein complexes.

Long-time scale accelerated molecular dynamic simulations in the M3 muscarinic receptor in Miao et al. (2015) further corroborated the notion that sodium ion bound to charged $\mathrm{D}^{2.50}$ residue confines the receptor mostly to an inactive state with reduced flexibility. In contrast, the $\mathrm{D}^{2.50}$-protonated receptor, which does not bind $\mathrm{Na}^{+}$could sample larger conformational space, including large-scale structural rearrangements of the transmembrane helices leading to active-like states. MD simulations in MOR receptor (Yuan et al., 2013) also supported the $\mathrm{Na}^{+}$trajectory pathway through a receptor entering the $D^{2.50}$ binding site from the extracellular side and then exiting at the intracellular site upon conformational changes and redistribution of internal water molecules. The simulations suggested that the egress path of $\mathrm{Na}^{+}$can also help to disrupt the ionic lock between $\mathrm{D}^{3.49}$ and $\mathrm{R}^{3.50}$ in the conserved "DRY" motif and thus can facilitate G-protein activation.

Another recent study performed for CXCR4 chemokine receptor simulations used replica exchange MD with enhanced sampling (Cong and Golebiowski, 2018), showing the special role of $\mathrm{Na}^{+}$coordinating $\mathrm{N}^{3.35}$ side chain in receptor activation and explaining the constitutive activation role of $\mathrm{N}^{3.35} \mathrm{~A}$ and $\mathrm{N}^{3.35} \mathrm{~S}$ mutations.

For histamine receptors, the MD simulations and the calculation of Gibbs energy of solvation (Wittmann et al., 2014) also show the preference for $\mathrm{D}^{2.50}$ binding of $\mathrm{Na}^{+}$in human H3-receptor (hH3R), which has an experimentally documented allosteric sensitivity to sodium ions. In contrast, the study suggests that the $\mathrm{L}^{7.42} \mathrm{Q}$ change between the hH3R and hH4R is responsible for different sodium dynamics in the two closely related receptor subtypes, even though all 16 residues of the sodium pocket are identical. While $\mathrm{Q}^{7.42}$, unique for $\mathrm{hH} 4 \mathrm{R}$ in not directly involved in sodium binding, it can disrupt the water-filled channel connecting orthosteric and allosteric sodium pocket in hH4R and kinetically block the sodium access, which may explain hH4R insensitivity to sodium effects.

MD simulations are now routinely used in many GPCR structural studies to decipher the functional effects of the $\mathrm{Na}^{+}$ion, e.g., for D4 dopamine receptor (Wang et al., 2017). The MD simulations of the DRD4 
inactive state suggest that sodium and the antagonist nemonapride can mutually stabilize each other's binding, in agreement with the increased affinity of nemonapridelike antagonists in the presence of sodium.

\section{Phylogenetic Analysis}

While the exceptional level of sequence and structure conservation of the sodium pocket in class A GPCRs has been characterized (Katritch et al., 2014), detailed study of variations in the sequence and structure of the pocket can be used to decipher interesting trends in the evolution of GPCR function. Thus, lack of conservation in the residues corresponding to sodium pocket of opsin receptors suggests different functional features of these receptors. Indeed, driven by much higher energies of photochemical switches in the covalent retinal ligand and the requirement for fast on-off switching, opsins have apparently lost their $\mathrm{Na}^{+}$binding and functional dependence. For GPCRs with dissolvable ligands, however, loss of $\mathrm{Na}^{+}$anchor residues in the receptor pocket of GPCR subtypes leads to loss of ligand-induced signaling, e.g., NTSR2 neurotensin receptor (NTSR2) is nonresponsive to neurotensin and presumably acts via dimerization with its fully functional and sodiumdependent NTSR1 neurotensin receptor subtype (Katritch et al., 2014).

Phylogenetic analysis also has been applied to make new insights into evolution of function in whole GPCR families, such as chemokine receptors (Taddese et al., 2018). The study used principal component analysis of sequence covariations in nested GPCR sequence sets to decipher evolutionary determinants of chemokine receptors. This approach identified residue positions $2.49,3.35$, and 7.45 as the hallmark positions that define the emergence of chemokine receptors and their subsequent divergence into homeostatic (e.g., CXCR4) and inflammatory (e.g., CCR5) receptors. Polar $\mathrm{N}^{3.35}$ and $\mathrm{S}^{3.39}$ in these key residue positions define high stability of the $\mathrm{Na}^{+}$binding in homeostatic receptors like CXCR4, while glycines $\mathrm{G}^{3.35}$ and $\mathrm{G}^{3.39}$ in these positions result in loose and weak $\mathrm{Na}^{+}$binding in CCR5 and other inflammatory receptors. Further analysis of chemokines in species also suggested that evolution of chemokine receptors might be driven, at least in part, by dramatic changes in the sodium binding mode. Thus, the ancient jawless fishes had a highly conserved sodium binding site, while this conservation was loosened during the divergence of the chemokine family in modern species.

\section{Unanswered Questions and Future Perspectives}

Despite dramatic progress in the understanding of the role of ions in GPCR function, allosteric regulation and fine tuning, numerous questions and venues of inquiry remain wide open.
First, it is still unclear how, with so many potential binding sites in GPCRs for various cations and anions (Strasser et al., 2015), the conserved $\mathrm{Na}^{+}$site became an almost universal site across the most populous and highly diverse class of class A GPCRs. Some hints were proposed in a recent study (Shalaeva et al., 2015) tracing sodium site evolution to the much more ancient 7TM family of prokaryotic sodium-translocating rhodopsins, though more comprehensive research is needed to clarify the origins and evolution of the $\mathrm{Na}^{+}$site in GPCRs, which may be facilitated by the flow of sequencing data from diverse prokaryotic and eukaryotic species.

Second, ascribing a precise functional role of sodium in the activation mechanism remains challenging. While its role as an NAM for agonist binding is most commonly studied, for the super-conserved site it absolutely is also required for effective agonistinduced signal transduction in class A GPCRs. The definitive experimental proof that not just the residues of the pocket, but the presence of $\mathrm{Na}^{+}$in the pocket itself, is critical for the function remains to be obtained. Because $\mathrm{Na}^{+}$is critical for the function of many cell components and has an obviously major impact on ion channels involved in GPCR signaling, such ultimate experimental proof requires very accurate and wellcontrolled experiments where removal of $\mathrm{Na}^{+}$and abrogation of its transmembrane gradient does not impact the assay itself.

Third, while the bulk of the structural and molecular modeling studies predict an extracellular entrance of $\mathrm{Na}^{+}$into the allosteric pocket and subsequent intracellular egress upon receptor activation, a definitive electrochemical or biochemical experiment directly demonstrating the transmembrane transfer of sodium by GPCRs across plasma membrane remains to be done. The key challenge for the electrophysiological assessment is an ultra-low current in this system, where a single charge transfer is occurring only once per GPCR activation event. Such currents are below the sensitivity thresholds of most methods conventionally used to characterize ion channels, pumps, and transporters and require either supersensitive electrophysiology or other approaches, e.g., using ${ }^{22} \mathrm{Na}^{+}$radioisotope.

Fourth, new approaches are needed to further investigate physiologic relevance of $\mathrm{Na}^{+}$modulation in some GPCRs and cell types. This includes further studies of gating potential effects in GPCR (Vickery et al., 2018), which may play a role in GPCR response to depolarization in neurons. Another interesting aspect is GPCR signaling in endosomes, where acidic environments can contribute to $\mathrm{D}^{2.50}$ protonation and explain prolonged, $\mathrm{pH}$-dependent signaling observed in this system. In general, the allosteric and the functional effects of sodium need to be incorporated as part of allosteric models and signaling pathway analysis, quantitatively explaining often unusual pharmacology of GPCR signaling in different cells and environments. 
Finally, while the first few examples of direct targeting $\mathrm{Na}^{+}$site by bitopic ligands have been emerging (Hori et al., 2018; S. Zaidi, T. Che, B. Roth, and V. Katritch, manuscript in preparation), there are myriad possibilities for using the $\mathrm{Na}^{+}$pocket in many GPCR targets to rationally design chemical probes with new properties and pharmacological profiles.

\section{Acknowledgments}

We would like to thank Drs. Ulrich Zachariae, Vadim Cherezov, Raymond C. Stevens, and Enrique Abola for helpful discussions.

\section{Authorship Contributions}

Participated in research design: Katritch, Roth.

Performed data analysis: Katritch, Zarzycka, Zaidi.

Wrote or contributed to the writing of the manuscript: Katritch, Roth, Zarzycka, Zaidi.

\section{References}

Barchad-Avitzur O, Priest Michael F, Dekel N, Bezanilla F, Parnas H, and Ben-Chaim Y (2016) A novel voltage sensor in the orthosteric binding site of the M2 muscarinic receptor. Biophys $J$ 111:1396-1408.

Batyuk A, Galli L, Ishchenko A, Han GW, Gati C, Popov PA, Lee MY, Stauch B, White TA, Barty A, et al. (2016) Native phasing of x-ray free-electron laser data for a G protein-coupled receptor. Sci Adv 2:e1600292

Ben-Chaim Y, Chanda B, Dascal N, Bezanilla F, Parnas I, and Parnas H (2006) Movement of 'gating charge' is coupled to ligand binding in a G-protein-coupled receptor. Nature 444:106-109.

Birdsall NJ, Burgen AS, Hulme EC, and Wells JW (1979) The effects of ions on the binding of agonists and antagonists to muscarinic receptors. $\mathrm{Br} J$ Pharmacol 67: 371-377.

Birk A, Rinne A, and Bunemann M (2015) Membrane potential controls the efficacy of catecholamine-induced beta1-adrenoceptor activity. J Biol Chem 290:27311-27320.

Calebiro D, Nikolaev VO, Persani L, and Lohse MJ (2010) Signaling by internalized G-protein-coupled receptors. Trends Pharmacol Sci 31:221-228.

Cao C, Tan Q, Xu C, He L, Yang L, Zhou Y, Zhou Y, Qiao A, Lu M, Yi C, et al. (2018) Structural basis for signal recognition and transduction by platelet-activatingfactor receptor. Nat Struct Mol Biol 25:488-495.

Capaldi S, Suku E, Antolini M, Di Giacobbe M, Giorgetti A, and Buffelli M (2018) Allosteric sodium binding cavity in GPR3: a novel player in modulation of $A \beta$ production. Sci Rep 8:11102.

Chang W, Tu C, Chen TH, Bikle D, and Shoback D (2008) The extracellular calciumsensing receptor (CaSR) is a critical modulator of skeletal development. Sci Signal 1:ra1.

Che T, Majumdar S, Zaidi SA, Ondachi P, McCorvy JD, Wang S, Mosier PD, Uprety R, Vardy E, Krumm BE, et al. (2018) Structure of the nanobody-stabilized active state of the kappa opioid receptor. Cell 172:55-67.

Cheng RKY, Fiez-Vandal C, Schlenker O, Edman K, Aggeler B, Brown DG, Brown GA, Cooke RM, Dumelin CE, Dore AS, et al. (2017a) Structural insight into allosteric modulation of protease-activated receptor 2. Nature 545:112-115.

Cheng RKY, Segala E, Robertson N, Deflorian F, Dore AS, Errey JC, Fiez-Vandal C, Marshall FH, and Cooke RM (2017b) Structures of human A1 and A2A adenosine receptors with xanthines reveal determinants of selectivity. Structure $\mathbf{2 5}$ $1275-1285$.

Christopher JA, Orgován Z, Congreve M, Doré AS, Errey JC, Marshall FH, Mason JS, Okrasa K, Rucktooa P, Serrano-Vega MJ, et al. (2019) Structure-based optimization strategies for G protein-coupled receptor (GPCR) allosteric modulators: a case study from analyses of new metabotropic glutamate receptor 5 (mGlu5) X-ray structures. J Med Chem 62:207-222.

Chung KY, Rasmussen SG, Liu T, Li S, DeVree BT, Chae PS, Calinski D, Kobilka BK, Woods VL Jr, and Sunahara RK (2011) Conformational changes in the G protein Gs induced by the beta2 adrenergic receptor. Nature 477:611-615.

Cong X and Golebiowski J (2018) Allosteric Na+-binding site modulates CXCR4 activation. Phys Chem Chem Phys 20:24915-24920.

Cooper DM, Londos C, Gill DL, and Rodbell M (1982) Opiate receptor-mediated inhibition of adenylate cyclase in rat striatal plasma membranes. $J$ Neurochem 38:1164-1167.

Costa T, Lang J, Gless C, and Herz A (1990) Spontaneous association between opioid receptors and GTP-binding regulatory proteins in native membranes: specific regulation by antagonists and sodium ions. Mol Pharmacol 37:383-394.

Costa T, Ogino Y, Munson PJ, Onaran HO, and Rodbard D (1992) Drug efficacy at guanine nucleotide-binding regulatory protein-linked receptors: thermodynamic interpretation of negative antagonism and of receptor activity in the absence of ligand. Mol Pharmacol 41:549-560.

Dehaye JP and Verhasselt V (1995) Interaction of amiloride with rat parotid muscarinic and alpha-adrenergic receptors. Gen Pharmacol 26:155-159.

Draper-Joyce CJ, Verma RK, Michino M, Shonberg J, Kopinathan A, Herenbrink CK, Scammells PJ, Capuano B, Abramyan AM, Thal DM, et al. (2018) The action of a negative allosteric modulator at the dopamine $\mathrm{D}_{2}$ receptor is dependent upon sodium ions. Sci Rep 8:1208.
Dudev T, Mazmanian K, and Lim C (2018) Competition between $\mathrm{Li}^{+}$and $\mathrm{Na}^{+}$in sodium transporters and receptors: which $\mathrm{Na}^{+}$-binding sites are "therapeutic" $\mathrm{Li}^{+}$ targets? Chem Sci 9:4093-4103.

Eddy MT, Gao ZG, Mannes P, Patel N, Jacobson KA, Katritch V, Stevens RC, and Wuthrich K (2018a) Extrinsic tryptophans as NMR probes of allosteric coupling in membrane proteins: application to the A2A adenosine receptor. $J A m$ Chem Soc 140:8228-8235.

Eddy MT, Lee MY, Gao ZG, White KL, Didenko T, Horst R, Audet M, Stanczak P, McClary KM, Han GW, et al. (2018b) Allosteric coupling of drug binding and intracellular signaling in the A2A adenosine receptor. Cell 172:68-80.

Eichel K and von Zastrow M (2018) Subcellular organization of GPCR signaling. Trends Pharmacol Sci 39:200-208.

Fenalti G, Giguere PM, Katritch V, Huang XP, Thompson AA, Cherezov V, Roth BL, and Stevens RC (2014) Molecular control of delta-opioid receptor signalling. Nature 506:191-196.

Flanagan CA, Zhou W, Chi L, Yuen T, Rodic V, Robertson D, Johnson M, Holland P, Millar RP, Weinstein $\mathrm{H}$, et al. (1999) The functional microdomain in transmembrane helices 2 and 7 regulates expression, activation, and coupling pathways of the gonadotropin-releasing hormone receptor. J Biol Chem 274:28880-28886.

Gao ZG and Ijzerman AP (2000) Allosteric modulation of A(2A) adenosine receptors by amiloride analogues and sodium ions. Biochem Pharmacol 60:669-676.

Gao ZG, Kim SK, Gross AS, Chen A, Blaustein JB, and Jacobson KA (2003a) Identification of essential residues involved in the allosteric modulation of the human A(3) adenosine receptor. Mol Pharmacol 63:1021-1031.

Gao ZG, Melman N, Erdmann A, Kim SG, Muller CE, IJzerman AP, and Jacobson KA (2003b) Differential allosteric modulation by amiloride analogues of agonist and antagonist binding at $\mathrm{A}(1)$ and $\mathrm{A}(3)$ adenosine receptors. Biochem Pharmacol 65:525-534.

Gao ZG, Verzijl D, Zweemer A, Ye K, Goblyos A, Jjzerman AP, and Jacobson KA (2011) Functionally biased modulation of A(3) adenosine receptor agonist efficacy and potency by imidazoquinolinamine allosteric enhancers. Biochem Pharmacol 82:658-668.

Ghanouni P, Schambye H, Seifert R, Lee TW, Rasmussen SG, Gether U, and Kobilka BK (2000) The effect of $\mathrm{pH}$ on beta(2) adrenoceptor function. Evidence for protonationdependent activation. J Biol Chem 275:3121-3127.

Godbole A, Lyga S, Lohse MJ, and Calebiro D (2017) Internalized TSH receptors en route to the TGN induce local Gs-protein signaling and gene transcription. Nat Commun 8:443.

Gutiérrez-de-Terán H, Massink A, Rodriguez D, Liu W, Han GW, Joseph JS, Katritch I, Heitman LH, Xia L, Ijzerman AP, et al. (2013) The role of a sodium ion binding site in the allosteric modulation of the $\mathrm{A}(2 \mathrm{~A})$ adenosine $\mathrm{G}$ protein-coupled receptor. Structure 21:2175-2185.

Hannan FM, Kallay E, Chang W, Brandi ML, and Thakker RV (2018) The calciumsensing receptor in physiology and in calcitropic and noncalcitropic diseases. Nat Rev Endocrinol 15:33-51.

Hauser AS, Attwood MM, Rask-Andersen M, Schioth HB, and Gloriam DE (2017) Trends in GPCR drug discovery: new agents, targets and indications. Nat Rev Drug Discov 16:829-842,

Hauser AS, Chavali S, Masuho I, Jahn LJ, Martemyanov KA, Gloriam DE, and Babu MM (2018) Pharmacogenomics of GPCR drug targets. Cell 172:41-54

Heitman LH, Ye K, Oosterom J, and Ijzerman AP (2008) Amiloride derivatives and a nonpeptidic antagonist bind at two distinct allosteric sites in the human gonadotropin-releasing hormone receptor. Mol Pharmacol 73:1808-1815

Hishinuma S, Kosaka K, Akatsu C, Uesawa Y, Fukui H, and Shoji M (2017) Asp73dependent and-independent regulation of the affinity of ligands for human histamine H-1 receptors by $\mathrm{Na}+$. Biochem Pharmacol 128:46-54.

Hoare SR, Coldwell MC, Armstrong D, and Strange PG (2000) Regulation of human $\mathrm{D}(1), \mathrm{d}(2$ (long)), $\mathrm{d}(2$ (short)), $\mathrm{D}(3)$ and $\mathrm{D}(4)$ dopamine receptors by amiloride and amiloride analogues. Br J Pharmacol 130:1045-1059.

Hoppe A, Marti-Solano M, Drabek M, Bunemann M, Kolb P, and Rinne A (2018) The allosteric site regulates the voltage sensitivity of muscarinic receptors. Cell Signal 42:114-126.

Hori T, Okuno T, Hirata K, Yamashita K, Kawano Y, Yamamoto M, Hato M, Nakamura M, Shimizu T, Yokomizo T, et al. (2018) Na(+)-mimicking ligands stabilize the inactive state of leukotriene B4 receptor BLT1. Nat Chem Biol 14:262-269.

Horstman DA, Brandon S, Wilson AL, Guyer CA, Cragoe EJ Jr, and Limbird LE (1990) An aspartate conserved among G-protein receptors confers allosteric regulation of alpha 2-adrenergic receptors by sodium. J Biol Chem 265:21590-21595.

Howard MJ, Hughes RJ, Motulsky HJ, Mullen MD, and Insel PA (1987) Interactions of amiloride with alpha- and beta-adrenergic receptors: amiloride reveals an allosteric site on alpha 2-adrenergic receptors. Mol Pharmacol 32:53-58.

Hu X, Wang Y, Hunkele A, Provasi D, Pasternak GW, and Filizola M (2019) Kinetic and thermodynamic insights into sodium ion translocation through the $\mu$-opioid receptor from molecular dynamics and machine learning analysis. PLoS Comput Biol 15:e1006689.

Huang W, Manglik A, Venkatakrishnan AJ, Laeremans T, Feinberg EN, Sanborn AL, Kato HE, Livingston KE, Thorsen TS, Kling RC, et al. (2015a) Structural insights into mu-opioid receptor activation. Nature 524:315-321.

Huang XP, Karpiak J, Kroeze WK, Zhu H, Chen X, Moy SS, Saddoris KA, Nikolova VD, Farrell MS, Wang S, et al. (2015b) Allosteric ligands for the pharmacologically dark receptors GPR68 and GPR65. Nature 527:477-483.

Insel PA, Tang C-M, Hahntow I, and Michel MC (2007) Impact of GPCRs in clinical medicine: monogenic diseases, genetic variants and drug targets. Biochim Biophys Acta 1768:994-1005.

Irannejad R, Tomshine JC, Tomshine JR, Chevalier M, Mahoney JP, Steyaert J, Rasmussen SG, Sunahara RK, El-Samad H, Huang B, et al. (2013) Conformational biosensors reveal GPCR signalling from endosomes. Nature 495:534-538.

Isberg V, de Graaf C, Bortolato A, Cherezov V, Katritch V, Marshall FH, Mordalski S, Pin JP, Stevens RC, Vriend G, et al. (2015) Generic GPCR residue numbers - aligning topology maps while minding the gaps. Trends Pharmacol Sci 36:22-31. 
Jiang JY, Nagaraju M, Meyer RC, Zhang L, Hamelberg D, Hall RA, Brown EM, Conn PJ, and Yang JJ (2014) Extracellular calcium modulates actions of orthosteric and allosteric ligands on metabotropic glutamate receptor 1alpha. $J$ Biol Chem 289:1649-1661.

Jiang Y, Huang Y, Wong HC, Zhou Y, Wang X, Yang J, Hall RA, Brown EM, and Yang JJ (2010) Elucidation of a novel extracellular calcium-binding site on metabotropic glutamate receptor 1 alpha\} (mGluR1\{alpha\}) that controls receptor activation. J Biol Chem 285:33463-33474.

Katritch V, Cherezov V, and Stevens RC (2013) Structure-function of the G proteincoupled receptor superfamily. Annu Rev Pharmacol Toxicol 53:531-556.

Katritch V, Fenalti G, Abola EE, Roth BL, Cherezov V, and Stevens RC (2014) Allosteric sodium in class A GPCR signaling. Trends Biochem Sci 39:233-244.

Kong H, Raynor K, Yasuda K, Bell GI, and Reisine T (1993) Mutation of an aspartate at residue 89 in somatostatin receptor subtype 2 prevents $\mathrm{Na}+$ regulation of agonist binding but does not alter receptor-G protein association. Mol Pharmacol 44:380-384.

Koshimizu TA, Kashiwazaki A, and Taniguchi J (2016) Combined sodium ion sensitivity in agonist binding and internalization of vasopressin V1b receptors. Sci Rep 6:25327.

Krumm BE, White JF, Shah P, and Grisshammer R (2015) Structural prerequisites for G-protein activation by the neurotensin receptor. Nat Commun 6:7895.

Kuppuraj G, Dudev M, and Lim C (2009) Factors governing metal-ligand distances and coordination geometries of metal complexes. J Phys Chem B $\mathbf{1 1 3}$ 2952-2960.

Lagerström MC and Schiöth HB (2008) Structural diversity of G protein-coupled receptors and significance for drug discovery [published correction appears in Nat Rev Drug Discov (2008) 7:542]. Nat Rev Drug Discov 7:339-357.

Leppik RA, Mynett A, Lazareno S, and Birdsall NJ (2000) Allosteric interactions between the antagonist prazosin and amiloride analogs at the human alpha(1A)adrenergic receptor. Mol Pharmacol 57:436-445.

Liu JJ, Horst R, Katritch V, Stevens RC, and Wuthrich K (2012a) Biased signaling pathways in beta2-adrenergic receptor characterized by 19F-NMR. Science $\mathbf{3 3 5}$ $1106-1110$

Liu J-P, Nakakura T, Tomura H, Tobo M, Mogi C, Wang J-Q, He X-D, Takano M, Damirin A, Komachi M, et al. (2010) Each one of certain histidine residues in G-protein-coupled receptor GPR4 is critical for extracellular proton-induced stimulation of multiple G-protein-signaling pathways. Pharmacol Res 61:499-505.

Liu W, Chun E, Thompson AA, Chubukov P, Xu F, Katritch V, Han GW, Roth CB, Heitman LH, AP IJ, et al. (2012b) Structural basis for allosteric regulation of GPCRs by sodium ions. Science 337:232-236.

Livingston KE, Stanczyk MA, Burford NT, Alt A, Canals M, and Traynor JR (2018) Pharmacologic evidence for a putative conserved allosteric site on opioid receptors. Mol Pharmacol 93:157-167.

Livingston KE and Traynor JR (2014) Disruption of the $\mathrm{Na}+$ ion binding site as a mechanism for positive allosteric modulation of the mu-opioid receptor. Proc Natl Acad Sci USA 111:18369-18374.

Lodish H, Berk A, and Zipursky S (2000) Molecular Cell Biology, W. H. Freeman, New York.

Ludwig MG, Vanek M, Guerini D, Gasser JA, Jones CE, Junker U, Hofstetter H, Wolf RM, and Seuwen K (2003) Proton-sensing G-protein-coupled receptors. Nature 425 93-98.

Luginina A, Gusach A, Marin E, Mishin A, Brouillette R, Popov P, Shiriaeva A, Besserer-Offroy E, Longpré J, Lyapina E, et al. (2019) Structure-based mechanism of cysteinyl leukotriene receptor inhibition by antiasthmatic drugs. Sci Adv in press.

Manglik A, Kruse AC, Kobilka TS, Thian FS, Mathiesen JM, Sunahara RK, Pardo L, Weis WI, Kobilka BK, and Granier S (2012) Crystal structure of the mu-opioid receptor bound to a morphinan antagonist. Nature 485:321-326.

Massink A, Gutiérrez-de-Terán H, Lenselink EB, Ortiz Zacarías NV, Xia L, Heitman LH, Katritch V, Stevens RC, and IJzerman AP (2015) Sodium ion binding pocket mutations and adenosine A2A receptor function. Mol Pharmacol 87:305-313.

Massink A, Louvel J, Adlere I, van Veen C, Huisman BJ, Dijksteel GS, Guo D, Lenselink EB, Buckley BJ, Matthews H, et al. (2016) 5 '-Substituted amiloride derivatives as allosteric modulators binding in the sodium ion pocket of the adenosine A2A receptor. J Med Chem 59:4769-4777.

Merk A, Bartesaghi A, Banerjee S, Falconieri V, Rao P, Davis MI, Pragani R, Boxer MB, Earl LA, Milne JLS, et al. (2016) Breaking cryo-EM resolution barriers to facilitate drug discovery. Cell 165:1698-1707.

Miao Y, Caliman AD, and McCammon JA (2015) Allosteric effects of sodium ion binding on activation of the $\mathrm{m} 3$ muscarinic g-protein-coupled receptor. Biophys $J$ 108:1796-1806.

Michino M, Free RB, Doyle TB, Sibley DR, and Shi L (2015) Structural basis for $\mathrm{Na}(+)$-sensitivity in dopamine D2 and D3 receptors. Chem Commun (Camb) 51 $8618-8621$.

Miller-Gallacher JL, Nehme R, Warne T, Edwards PC, Schertler GF, Leslie AG, and Tate CG (2014) The $2.1 \AA$ resolution structure of cyanopindolol-bound $\beta 1$ adrenoceptor identifies an intramembrane $\mathrm{Na}+$ ion that stabilises the ligand-free receptor. PLoS One 9:e92727.

Möller I, Murali R, Müller H, Wiesner T, Jackett LA, Scholz SL, Cosgarea I, van de Nes JA, Sucker A, Hillen U, et al. (2017) Activating cysteinyl leukotriene receptor 2 (CYSLTR2) mutations in blue nevi. Mod Pathol 30:350-356.

Moore AR, Ceraudo E, Sher JJ, Guan Y, Shoushtari AN, Chang MT, Zhang JQ, Walczak EG, Kazmi MA, Taylor BS, et al. (2016) Recurrent activating mutations of G-protein-coupled receptor CYSLTR2 in uveal melanoma. Nat Genet 48:675-680.

Navarro-Polanco RA, Moreno Galindo EG, Ferrer-Villada T, Arias M, Rigby JR, Sanchez-Chapula JA, and Tristani-Firouzi M (2011) Conformational changes in the M2 muscarinic receptor induced by membrane voltage and agonist binding. J Physiol 589:1741-1753.

Neve KA (1991) Regulation of dopamine D2 receptors by sodium and pH. Mol Pharmacol 39:570-578.
Neve KA, Cox BA, Henningsen RA, Spanoyannis A, and Neve RL (1991) Pivotal role for aspartate- 80 in the regulation of dopamine D2 receptor affinity for drugs and inhibition of adenylyl cyclase. Mol Pharmacol 39:733-739.

Nunez D, Kumar R, and Hanahan DJ (1989) Inhibition of [3H]platelet activating factor (PAF) binding by $\mathrm{Zn} 2+$ : a possible explanation for its specific PAF antiaggregating effects in human platelets. Arch Biochem Biophys 272:466-475.

Pasternak GW, Snowman AM, and Snyder SH (1975) Selective enhancement of [3H] opiate agonist binding by divalent cations. Mol Pharmacol 11:735-744.

Pauwels PJ (1997) Competitive and silent antagonism of recombinant 5-HT1B receptors by amiloride. Gen Pharmacol 29:749-751.

Pert CB, Pasternak G, and Snyder SH (1973) Opiate agonists and antagonists discriminated by receptor binding in brain. Science 182:1359-1361.

Pert CB and Snyder SH (1974) Opiate receptor binding of agonists and antagonists affected differentially by sodium. Mol Pharmacol 10:868-879.

Popov P, Kozlovskii I, and Katritch V (2019) Computational design for thermostabilization of GPCRs. Curr Opin Struct Biol 55:25-33.

Popov P, Peng Y, Shen L, Stevens RC, Cherezov V, Liu ZJ, and Katritch V (2018) Computational design of thermostabilizing point mutations for $\mathrm{G}$ protein-coupled receptors. eLife 7:e34729.

Quitterer U, AbdAlla S, Jarnagin K, and Müller-Esterl W (1996) Na+ ions binding to the bradykinin B2 receptor suppress agonist-independent receptor activation. Biochemistry 35:13368-13377.

Radu CG, Nijagal A, McLaughlin J, Wang L, and Witte ON (2005) Differential proton sensitivity of related $\mathrm{G}$ protein-coupled receptors $\mathrm{T}$ cell death-associated gene 8 and G2A expressed in immune cells. Proc Natl Acad Sci USA 102:1632-1637.

Rahmeh R, Damian M, Cottet M, Orcel H, Mendre C, Durroux T, Sharma KS, Durand G, Pucci B, Trinquet E, et al. (2012) Structural insights into biased G protein-coupled receptor signaling revealed by fluorescence spectroscopy. Proc Natl Acad Sci USA 109:6733-6738.

Rasmussen SG, DeVree BT, Zou Y, Kruse AC, Chung KY, Kobilka TS, Thian FS, Chae PS, Pardon E, Calinski D, et al. (2011) Crystal structure of the beta2 adrenergic receptor-Gs protein complex. Nature 477:549-555.

Rinne A, Birk A, and Bunemann M (2013) Voltage regulates adrenergic receptor function. Proc Natl Acad Sci USA 110:1536-1541.

Rinne A, Mobarec JC, Mahaut-Smith M, Kolb P, and Bunemann M (2015) The mode of agonist binding to a $\mathrm{G}$ protein-coupled receptor switches the effect that voltage changes have on signaling. Sci Signal 8:ra110.

Rosenbaum DM, Zhang C, Lyons JA, Holl R, Aragao D, Arlow DH, Rasmussen SG, Choi HJ, Devree BT, Sunahara RK, et al, (2011) Structure and function of an irreversible agonist-beta(2) adrenoceptor complex. Nature 469:236-240.

Rosenberger LB, Yamamura HI, and Roeske WR (1980) Cardiac muscarinic cholin ergic receptor binding is regulated by $\mathrm{Na}+$ and guanyl nucleotides. $J$ Biol Chem 255:820-823.

Roth BL (2019) Molecular pharmacology of metabotropic receptors targeted by neuropsychiatric drugs. Nat Struct Mol Biol 26:535-544.

Roth BL, Laskowski MB, and Coscia CJ (1981) Evidence for distinct subcellular sites of opiate receptors. Demonstration of opiate receptors in smooth microsomal fractions isolated from rat brain. J Biol Chem 256:10017-10023.

Sato S, Huang XP, Kroeze WK, and Roth BL (2016) Discovery and characterization of novel GPR39 agonists allosterically modulated by zinc. Mol Pharmacol 90: $726-737$.

Schiffmann A and Gimpl G (2018) Sodium functions as a negative allosteric modulator of the oxytocin receptor. Biochim Biophys Acta Biomembr 1860:1301-1308.

Schöppe J, Ehrenmann J, Klenk C, Rucktooa P, Schütz M, Doré AS, and Plückthun A (2019) Crystal structures of the human neurokinin 1 receptor in complex with clinically used antagonists. Nat Commun 10:17.

Sealfon SC, Chi L, Ebersole BJ, Rodic V, Zhang D, Ballesteros JA, and Weinstein H (1995) Related contribution of specific helix 2 and 7 residues to conformational activation of the serotonin 5-HT2A receptor. J Biol Chem 270:16683-16688.

Seifert R and Wenzel-Seifert K (2001) Unmasking different constitutive activity of four chemoattractant receptors using $\mathrm{Na}+$ as universal stabilizer of the inactive (R) state. Receptors Channels 7:357-369.

Selent J, Sanz F, Pastor M, and De Fabritiis G (2010) Induced effects of sodium ions on dopaminergic G-protein coupled receptors. PLoS Comput Biol 6:e1000884.

Selley DE, Cao CC, Liu Q, and Childers SR (2000) Effects of sodium on agonist efficacy for G-protein activation in mu-opioid receptor-transfected $\mathrm{CHO}$ cells and rat thalamus. Br J Pharmacol 130:987-996.

Selvam B, Shamsi Z, and Shukla D (2018) Universality of the sodium ion binding mechanism in class A G-protein-coupled receptors, Angew Chem Int Ed Engl 57, pp 3048-3053.

Shalaeva DN, Galperin MY, and Mulkidjanian AY (2015) Eukaryotic G proteincoupled receptors as descendants of prokaryotic sodium-translocating rhodopsins. Biol Direct 10:63.

Shang Y, LeRouzic V, Schneider S, Bisignano P, Pasternak GW, and Filizola M (2014) Mechanistic insights into the allosteric modulation of opioid receptors by sodium ions. Biochemistry 53:5140-5149.

Shihoya W, Nishizawa T, Yamashita K, Inoue A, Hirata K, Kadji FMN, Okuta A Tani K, Aoki J, Fujiyoshi Y, et al. (2017) X-ray structures of endothelin ETB receptor bound to clinical antagonist bosentan and its analog. Nat Struct Mol Biol 24: $758-764$

Shimamura T, Shiroishi M, Weyand S, Tsujimoto H, Winter G, Katritch V, Abagyan R, Cherezov V, Liu W, Han GW, et al. (2011) Structure of the human histamine H1 receptor complex with doxepin. Nature 475:65-70.

Silve C, Petrel C, Leroy C, Bruel H, Mallet E, Rognan D, and Ruat M (2005) Delineating a $\mathrm{Ca} 2+$ binding pocket within the venus flytrap module of the human calcium-sensing receptor. J Biol Chem 280:37917-37923.

Simon EJ and Groth J (1975) Kinetics of opiate receptor inactivation by sulfhydryl reagents: evidence for conformational change in presence of sodium ions. Proc Natl Acad Sci USA 72:2404-2407.

Spiegel AM and Weinstein LS (2004) Inherited diseases involving G proteins and G protein-coupled receptors. Annu Rev Med 55:27-39. 
Storjohann L, Holst B, and Schwartz TW (2008) Molecular mechanism of Zn2+ agonism in the extracellular domain of GPR39. FEBS Lett 582:2583-2588.

Strader CD, Sigal IS, Candelore MR, Rands E, Hill WS, and Dixon RA (1988) Conserved aspartic acid residues 79 and 113 of the beta-adrenergic receptor have different roles in receptor function. J Biol Chem 263:10267-10271.

Strasser A, Wittmann HJ, Schneider EH, and Seifert R (2015) Modulation of GPCRs by monovalent cations and anions. Naunyn Schmiedebergs Arch Pharmacol 388:363-380.

Suga H and Ehlert FJ (2013) Effects of asparagine mutagenesis of conserved aspartic acids in helix 2 (D2.50) and 3 (D3.32) of M1-M4 muscarinic receptors on the irreversible binding of nitrogen mustard analogs of acetylcholine and McN-A-343. Biochemistry 52:4914-4928.

Suno R, Kimura KT, Nakane T, Yamashita K, Wang J, Fujiwara T, Yamanaka Y, Im D, Horita S, Tsujimoto H, et al. (2018a) Crystal structures of human orexin 2 receptor bound to the subtype-selective antagonist EMPA. Structure 26:7-19.

Suno R, Lee S, Maeda S, Yasuda S, Yamashita K, Hirata K, Horita S, Tawaramoto MS, Tsujimoto H, Murata T, et al. (2018b) Structural insights into the subtype-selective antagonist binding to the M2 muscarinic receptor. Nat Chem Biol 14:1150-1158.

Taddese B, Deniaud M, Garnier A, Tiss A, Guissouma H, Abdi H, Henrion D, and Chabbert M (2018) Evolution of chemokine receptors is driven by mutations in the sodium binding site. PLoS Comput Biol 14:e1006209.

Tao YX, Abell AN, Liu X, Nakamura K, and Segaloff DL (2000) Constitutive activation of $\mathrm{g}$ protein-coupled receptors as a result of selective substitution of a conserved leucine residue in transmembrane helix iii. Mol Endocrinol 14:1272-1282.

Teller DC, Okada T, Behnke CA, Palczewski K, and Stenkamp RE (2001) Advances in determination of a high-resolution three-dimensional structure of rhodopsin, a model of G-protein-coupled receptors (GPCRs). Biochemistry 40:7761-7772.

Thompson AA, Liu W, Chun E, Katritch V, Wu H, Vardy E, Huang XP, Trapella C, Guerrini R, Calo G, et al. (2012) Structure of the nociceptin/orphanin FQ receptor in complex with a peptide mimetic. Nature 485:395-399.

Toyoda Y, Morimoto K, Suno R, Horita S, Yamashita K, Hirata K, Sekiguchi Y, Yasuda S, Shiroishi M, Shimizu T, et al. (2019) Ligand binding to human prostaglandin E receptor EP4 at the lipid-bilayer interface. Nat Chem Biol 15:18-26.

Tsai BS and Lefkowitz RJ (1978) Agonist-specific effects of monovalent and divalent cations on adenylate cyclase-coupled alpha adrenergic receptors in rabbit platelets. Mol Pharmacol 14:540-548.

Valentin-Hansen L, Frimurer TM, Mokrosinski J, Holliday ND, and Schwartz TW (2015) Biased Gs versus Gq proteins and beta-arrestin signaling in the NK1 receptor determined by interactions in the water hydrogen bond network. $J$ Biol Chem 290:24495-24508.

Vassart G and Costagliola S (2011) G protein-coupled receptors: mutations and endocrine diseases. Nat Rev Endocrinol 7:362-372.

Vickery ON, Carvalheda CA, Zaidi SA, Pisliakov AV, Katritch V, and Zachariae U (2018) Intracellular transfer of $\mathrm{Na}(+)$ in an active-state G-protein-coupled receptor. Structure 26:171-180.

Vickery ON, Machtens JP, Tamburrino G, Seeliger D, and Zachariae U (2016) Structural mechanisms of voltage sensing in G protein-coupled receptors. Structure 24:997-1007.

Vilardaga JP, Jean-Alphonse FG, and Gardella TJ (2014) Endosomal generation of cAMP in GPCR signaling. Nat Chem Biol 10:700-706.

Wang C, Wu H, Katritch V, Han GW, Huang XP, Liu W, Siu FY, Roth BL, Cherezov V, and Stevens RC (2013) Structure of the human smoothened receptor bound to an antitumour agent. Nature 497:338-343.

Wang S, Wacker D, Levit A, Che T, Betz RM, McCorvy JD, Venkatakrishnan AJ, Huang XP, Dror RO, Shoichet BK, et al. (2017) D4 dopamine receptor highresolution structures enable the discovery of selective agonists. Science $\mathbf{3 5 8}$ 381-386

Warne T, Moukhametzianov R, Baker JG, Nehme R, Edwards PC, Leslie AG, Schertler GF, and Tate CG (2011) The structural basis for agonist and partial agonist action on a beta(1)-adrenergic receptor. Nature 469:241-244.

White AD, Fang F, Jean-Alphonse FG, Clark LJ, An H-J, Liu H, Zhao Y, Reynolds SL, Lee S, Xiao K, et al. (2019) $\mathrm{Ca}^{2+}$ allostery in PTH-receptor signaling. Proc Natl Acad Sci USA 116:3294-3299.
White JF, Noinaj N, Shibata Y, Love J, Kloss B, Xu F, Gvozdenovic-Jeremic J, Shah P, Shiloach J, Tate CG, et al. (2012) Structure of the agonist-bound neurotensin receptor. Nature 490:508-513.

White KL, Eddy MT, Gao ZG, Han GW, Lian T, Deary A, Patel N, Jacobson KA, Katritch V, and Stevens RC (2018) Structural connection between activation microswitch and allosteric sodium site in GPCR signaling. Structure 26:259-269.

Wingler LM, McMahon C, Staus DP, Lefkowitz RJ, and Kruse AC (2019) Distinctive activation mechanism for angiotensin receptor revealed by a synthetic nanobody. Cell 176:479-490.e12.

Wittmann HJ, Seifert R, and Strasser A (2014) Sodium binding to hH3R and hH 4R-a molecular modeling study. J Mol Model 20:2394.

Wu H, Wacker D, Mileni M, Katritch V, Han GW, Vardy E, Liu W, Thompson AA, Huang XP, Carroll FI, et al. (2012) Structure of the human kappa-opioid receptor in complex with JDTic. Nature 485:327-332.

Xu W, Ozdener F, Li JG, Chen C, de Riel JK, Weinstein H, and Liu-Chen LY (1999) Functional role of the spatial proximity of Asp114(2.50) in TMH 2 and Asn332(7.49) in TMH 7 of the mu opioid receptor. FEBS Lett 447:318-324.

Yang LV, Radu CG, Roy M, Lee S, McLaughlin J, Teitell MA, Iruela-Arispe ML, and Witte ON (2007) Vascular abnormalities in mice deficient for the G proteincoupled receptor GPR4 that functions as a pH sensor. Mol Cell Biol 27:1334-1347.

Yang S, Wu Y, Xu TH, de Waal PW, He Y, Pu M, Chen Y, DeBruine ZJ, Zhang B, Zaidi SA, et al. (2018) Crystal structure of the Frizzled 4 receptor in a ligand-free state. Nature 560:666-670.

Yao XJ, Velez Ruiz G, Whorton MR, Rasmussen SG, DeVree BT, Deupi X, Sunahara RK, and Kobilka B (2009) The effect of ligand efficacy on the formation and stability of a GPCR-G protein complex. Proc Natl Acad Sci USA 106:9501-9506.

Yasuda S, Kajiwara Y, Toyoda Y, Morimoto K, Suno R, Iwata S, Kobayashi T, Murata T, and Kinoshita M (2017) Hot-spot residues to be mutated common in G proteincoupled receptors of class A: identification of thermostabilizing mutations followed by determination of three-dimensional structures for two example receptors. J Phys Chem B 121:6341-6350.

Ye L, Neale C, Sljoka A, Lyda B, Pichugin D, Tsuchimura N, Larda ST, Pomes R, Garcia AE, Ernst OP, et al. (2018) Mechanistic insights into allosteric regulation of the A2A adenosine $\mathrm{G}$ protein-coupled receptor by physiological cations. Nat Commun 9:1372.

Yuan S, Filipek S, Palczewski K, and Vogel H (2014) Activation of G-protein-coupled receptors correlates with the formation of a continuous internal water pathway. Nat Commun 5:4733.

Yuan S, Vogel H, and Filipek S (2013) The role of water and sodium ions in the activation of the $\mu$-opioid receptor, Angew Chem Int Ed Engl 52, pp 10112-10115. Zhang C, Srinivasan Y, Arlow DH, Fung JJ, Palmer D, Zheng Y, Green HF, Pandey A, Dror RO, Shaw DE, et al. (2012) High-resolution crystal structure of human protease-activated receptor 1. Nature 492:387-392.

Zhang D, Gao ZG, Zhang K, Kiselev E, Crane S, Wang J, Paoletta S, Yi C, Ma L, Zhang W, et al. (2015a) Two disparate ligand-binding sites in the human P2Y1 receptor. Nature 520:317-321.

Zhang H, Han GW, Batyuk A, Ishchenko A, White KL, Patel N, Sadybekov A Zamlynny B, Rudd MT, Hollenstein K, et al. (2017) Structural basis for selectivity and diversity in angiotensin II receptors. Nature 544:327-332.

Zhang H, Unal H, Gati C, Han GW, Liu W, Zatsepin NA, James D, Wang D, Nelson G, Weierstall U, et al. (2015b) Structure of the Angiotensin receptor revealed by serial femtosecond crystallography. Cell 161:833-844.

Zhang J, Zhang K, Gao ZG, Paoletta S, Zhang D, Han GW, Li T, Ma L, Zhang W, Muller CE, et al. (2014) Agonist-bound structure of the human P2Y12 receptor Nature 509:119-122.

Zhao LH, Ma S, Sutkeviciute I, Shen DD, Zhou XE, de Waal PW, Li CY, Kang Y, Clark LJ, Jean-Alphonse FG, et al. (2019) Structure and dynamics of the active human parathyroid hormone receptor-1. Science 364:148-153.

Zheng Y, Han GW, Abagyan R, Wu B, Stevens RC, Cherezov V, Kufareva I, and Handel TM (2017) Structure of CC chemokine receptor 5 with a potent chemokine antagonist reveals mechanisms of chemokine recognition and molecular mimicry by HIV. Immunity 46:1005-1017. 